\title{
"Stick to Sports": Evidence from Sports Media on the Origins and Consequences of Newly Politicized Attitudes
}

\author{
Erik Peterson and Manuela Muñoz* \\ Texas A\&M University \\ Department of Political Science
}

\section{Forthcoming at Political Communication}

\begin{abstract}
Politics now intrudes into many aspects of social life. How does this occur and what are its consequences? We study the sources of politicized attitudes towards ESPN, a sports media outlet involved in controversies where politics and sports intersect, and consider their implications for sports news use. We assess two potential contributors to politicized attitudes towards ESPN: exposure to political media criticizing the network and encounters with its sports coverage. In survey-linked web browsing data and a survey experiment, exposure to political media led the public to evaluate ESPN in political terms, showing messages from political elites can affect opinions of entertainment media. In contrast, exposure to ESPN's typical sports coverage failed to alter views of the network. We also find these newly politicized attitudes do not reduce use of ESPN, demonstrating the intrusion of politics into a seemingly apolitical setting may not displace other considerations underlying behavior.
\end{abstract}

\footnotetext{
${ }^{*}$ Corresponding author email: erik.peterson@tamu.edu. Erik Peterson is an Assistant Professor of Political Science at Texas A\&M University. Manuela Muñoz is a graduate student in Political Science at Texas A\&M University. The authors thank Allison Archer, Johanna Dunaway and Maxwell Allamong for their comments and Texas A\&M's College of Liberal Arts, the Bill Lane Center for the American West, the Hoover Institution, and the Knight Foundation for financial support.
} 


\begin{abstract}
Politics now intrudes into many aspects of social life. How does this occur and what are its consequences? We study the sources of politicized attitudes towards ESPN, a sports media outlet involved in controversies where politics and sports intersect, and consider their implications for sports news use. We assess two potential contributors to politicized attitudes towards ESPN: exposure to political media criticizing the network and encounters with its sports coverage. In survey-linked web browsing data and a survey experiment, exposure to political media led the public to evaluate ESPN in political terms, showing messages from political elites can affect opinions of entertainment media. In contrast, exposure to ESPN's typical sports coverage failed to alter views of the network. We also find these newly politicized attitudes do not reduce use of ESPN, demonstrating the intrusion of politics into a seemingly apolitical setting may not displace other considerations underlying behavior.
\end{abstract}


The boundary between political and non-political aspects of daily life is porous and contested. Researchers have long sought to define this border (Brody and Sniderman 1977, Fitzgerald 2013, Settle 2018) and understand the "political translation" that expands the relevance of political attitudes (Campbell et al. 1960, 29-32). Politics now appears to intrude into many seemingly apolitical decisions. Studies of affective polarization demonstrate the public's dislike of their political opponents (Mason 2018, Iyengar et al. 2019) spills into relationships, religious practice, health care use and employment decisions (Huber and Malhotra 2017, Margolis 2017, McConnell et al. 2018, Panagopoulos et al. 2020, Krupenkin 2021). Politics can also affect consumer decision-making (Shah et al. 2007, Newman and Bartels 2011, DellaPosta et al. 2015, Endres and Panagopoulos 2017, Kam and Deichert 2020).

Yet, fundamental questions about this process remain unanswered. In many instances politicization occurs after researchers introduce political cues into an apolitical setting (e.g., Iyengar and Westwood 2015, Shafranek 2021), offering limited insight into factors that bring about politicization when direct political cues are unavailable (but see Lee 2021, HiaeshutterRice ND). Many studies also assess politicization using attitudinal measures, leaving the behavioral implications of newly politicized attitudes unclear.

How does politicization happen and what are its consequences? We study the public's attitudes and behavior towards ESPN, a sports news outlet involved in recent controversies were sports and politics intersect. In the wake of these controversies, a partisan divide in assessments of ESPN has developed, with Republicans more likely to evaluate it negatively than Democrats (Clavio and Vooris 2018). It is important to understand how this process of politicization unfolded for several reasons. Broadly, this case aligns with other recent instances in which political divides have spilled into popular culture (Settle 2018, Hetherington and Weiler 2018). More specifically, it is one of many instances where politics has become salient in the context of sports (Towler et al. 2020, Serazio 2019, Thorson and Serazio 2018) and is part of an ongoing debate about whether athletes and sports media should engage with political issues or instead "stick to sports" (Serazio and Thorson 2020). 
We theorize two avenues through which politicized views of ESPN could develop. First, politicization may be facilitated by messages from political media that introduce political considerations into assessments of ESPN, in this case a process of asymmetric polarization that involved extensive critiques of the sports network on right-leaning political media sources. Second, politicization may happen due to exposure to ESPN's sports coverage. We assess these potential sources of politicized attitudes towards ESPN, and their implications for sports news use, with an observational study of web browsing and a survey experiment.

Across these studies, critiques from right-leaning political media led the public to evaluate ESPN in political terms. In contrast, exposure to ESPN's typical sports coverage did not politicize evaluations of the network. The survey experiment provides some evidence sports news foregrounding political and social issues can generate politicization. However, in a content analysis politicized sports coverage is a minuscule share of the news on ESPN suggesting it makes a small contribution to politicization. Looking beyond attitudes, we find those holding politicized assessments of ESPN are no less willing to consume its coverage. Interest in sports, not partisanship or politicized attitudes, is the main predictor of use. The browsing data offer no evidence of a partisan divide in web traffic to ESPN's website.

Our findings about the origins of politicized attitudes towards ESPN, and their implications for behavior, contribute to understanding elite-driven opinion formation, affective polarization and political consumerism. We demonstrate the influence of political elites and partisan media extends beyond policy views (Levendusky 2013) and assessments of political media (Archer 2020, Ladd 2010) into views of an entertainment media outlet. As these politicized attitudes do not translate into an aversion to consuming ESPN's sports coverage, we also show the need to assess both attitudes and behavior to understand politicization.

\section{Defining Politicization}

We use a definition of politicization encompassing two aspects of academic and popular discussion. First, politicization occurs when the public directly associates an entity with politics, broadly speaking, or certain political concepts. Under this definition, politicization 
increases when more people see a political concept as relevant to evaluating an entity. This follows previous work asking people to determine whether various issues or hobbies have a political association (Fitzgerald 2013, Settle 2018).

Second, politicization occurs when political attitudes predict opinions of a formerly apolitical entity. This more indirect approach follows discussion in The American Voter describing the increasingly strong relationship between partisanship and views of Dwight Eisenhower that developed as he moved from apolitical war hero to partisan presidential nominee (Campbell et al. 1960, 29-32). This conceptualization of politicization has contemporary relevance given studies of the relationship between partisanship and brand assessments (DellaPosta et al. 2015, Shah et al. 2007) and evidence partisan cues affect non-political decisions (McConnell et al. 2018, Engelhardt and Utych 2020, Panagopoulos et al. 2020).

There are ways to operationalize each aspect of politicization in this case. Under the first, we will say attitudes towards ESPN are politicized if members of the public evaluate the sports network as having an ideological slant, like assessments they might make of political media. Using the second, we will consider attitudes towards ESPN politicized if variables such as partisanship or political media use predict evaluations of the sports network.

Here we emphasize our focus on public perceptions. When we speak of limited politicization in this sense, it means the public's views of ESPN are not associated with political variables or the public does not perceive political considerations relevant for evaluating ESPN. In no way does this indicate an assessment of sports, or entertainment media in general, as apolitical (e.g., see Kim ND). Indeed, an important literature establishes many inherently political elements of sports, whether recognized by the mass public or not. The negative reactions to athletes engaging with social issues, such as Colin Kaepernick's protests against police violence (Towler et al. 2020), and, concurrently, the muted public response to politically-relevant messages around patriotism and support for the US military conveyed during sporting events (Serazio 2019), illustrate the presence of politics throughout sports. In this sense, we seek to explain how this aspect of sports becomes relevant for public opinion. 


\section{Pathways to Politicization}

In previous work, political attitudes gain relevance in new settings after researchers introduce direct political cues. For instance, if applicants indicate their partisanship on a resume, it affects how they are evaluated (Iyengar and Westwood 2015). This shows politics can matter in such situations, but the generalizability of these findings to other aspects of everyday life is unclear. People routinely disguise their political views to avoid negative reactions in social settings (Settle and Carlson 2019, Carlson and Settle 2016, Klar and Krupnikov 2016) and, in many circumstances, clear political cues of the type provided in previous studies of political spillovers may not be available.

How might political considerations become relevant for public opinion in situations where they were previously not? We consider two avenues. First, messages from politicians and political media can introduce political considerations into a new setting. Such rhetoric may link a formerly apolitical entity with an ideological or partisan viewpoint. As we later discuss, our focus here is coverage of ESPN in right-leaning political media portraying the sports network as liberal. This aligns with accounts of the media as contributors to politicization (Campbell et al. 1960, 29-32). Moreover, it is consistent with evidence showing political elites and partisan media influence public opinion (e.g., Levendusky 2013), although we depart from other studies by considering whether political actors can affect opinion outside the political domain.

Second, experiences with a formerly non-political entity may evoke political considerations, without the need for elites to make a connection. Fitzgerald (2013) finds some topics are characterized as political even if they do not directly relate to government. Settle (2018) shows many brands and lifestyle choices are "implicitly political" and perceived to have an association with a political party (see also Lee 2021, Hiaeshutter-Rice et al. ND). In the case we consider, this would happen if people perceived political implications to ESPN's sports news. 


\section{Implications of Newly Politicized Attitudes}

Beyond considering how attitudes become politicized, it is important to understand their consequences. Prior evidence is mixed. Many political consumerism studies find that political considerations influence attitudes towards products, but do not link them to consumption (Newman and Bartels 2011, Shah et al. 2007, Endres et al. 2021). There is evidence that political cues, when researchers provide them, can shape apolitical behaviors. McConnell et al. (2018) find information revealing shared partisanship makes consumers more likely to make an online purchase (see also Kam and Deichert 2020). Similarly, partisanship influences online dating behavior (Huber and Malhotra 2017) and health care use (Krupenkin 2021).

The influence of political attitudes on non-political activity is weaker when links with politics are offset by other criteria. McGrath (2017) finds partisan divides in economic perceptions in surveys do not translate into differences in real-world consumption. Mummolo and Nall (2017) show partisans express an affinity for neighborhoods that align with their political views in surveys, but find affordability and neighborhood quality constrain partisan views from influencing moving decisions.

Here we examine whether holding politicized views of ESPN affects consumption of its sports news. One possibility is that ESPN's politicization has reduced interest in its content

among Republicans and those perceiving the network as liberal (Ramachandran 2018). Alternatively, politicization may not decrease interest in ESPN's sports coverage, as in other settings where partisan divides in attitudes fail to shape behavior.

\section{The Politicization of ESPN's Reputation}

ESPN began covering sports on cable television in 1979. From initial broadcasts of "ping-pong tournaments and slow-pitch softball games" (Miller and Shales 2011, 67), the network rose to dominate the sports media landscape. In 2019 ESPN was the highest rated entertainment network on cable television, averaging 1.8 million daily viewers (Andreeva and Johnson 2019) and the most popular sports website in the United States, with 82 million 
unique visitors in July 2019 (Smith 2019).

During the past several years, the network has been at the forefront of controversies where politics and sports intersect. In 2015 ESPN awarded retired Olympian Caitlyn Jenner, who had recently come out as a transgender woman, with the Arthur Ashe Courage Award. This decision was criticized, with calls from right-leaning political media for ESPN to avoid bringing social issues into its coverage (Strauss 2017).

Other controversies center on comments made by ESPN employees. In 2017, SportsCenter anchor Jemele Hill called President Donald Trump a "white supremacist" on social media (Ramachandran 2018), which led Trump to later tweet that ESPN was losing viewers and "paying a really big price for its politics" (Gleeson 2017). In 2019, Dan Le Batard, an ESPN television and radio host, was suspended after criticizing Trump's "dangerous rhetoric" directed towards Representative Ilhan Omar (Traina 2019).

In the wake of these events, ESPN's reputation has been politicized. In a September 2017 YouGov poll $62 \%$ of Republicans believed ESPN should fire Hill, while only $8 \%$ of Democrats took this position (YouGov 2017). In YouGov panel data tracking brand sentiment, Democrats and Republicans evaluated ESPN similarly until 2015. After this a partisan gap in ESPN's approval emerged, with Republicans growing more negative towards the sports network (Hiebert 2017). In a 2017 survey Clavio and Vooris (2018) found conservatives were more likely to perceive ESPN's coverage as biased. Original surveys we later consider, which cover 2018-2020, reveal a continued partisan divide in assessments of ESPN.

\section{Explaining ESPN's Politicization}

Sports and politics have frequently intersected in recent years, such as political activism by athletes like Colin Kaepernick (e.g., Serazio and Thorson 2020, Towler et al. 2020). Here we consider instances in which ESPN was the focal point of the intrusion of politics into sports. Our later content analysis of discussions of ESPN on political media reveals a sustained critique of the entire network from right-leaning media sources. We note that, due to the specifics of this case, our focus is necessarily on asymmetric polarization as we devote 
attention to the consequences of right-leaning media critiques of ESPN as liberal. In our concluding discussion we discuss the generalizability of this case to other settings. Before proceeding, we highlight how this fits our discussion of politicized attitudes.

\section{Discussions of ESPN on Political Media}

Commentary about ESPN on right-leaning political media represents a potential source of politicization. There are many examples in recent years (e.g., Strauss 2017, Falcous et al. 2019, Serazio 2019). For instance, Tucker Carlson opened his Fox News show on September 13, 2017 with: "You probably thought ESPN stood for entertainment and sports programming network. Now it looks like endless stupid political nagging."

To examine these messages, we parsed transcripts of Fox News shows referencing ESPN from 2005 to 2019 and recorded the number of shows invoking political considerations when discussing the sports network 1 While we later consider online news use, we consider cable television here to assess such commentary over a long window.

We identified 128 Fox News shows with politicized mentions of ESPN. These fell into three main categories. Most prominent was criticism of perceived political motivations behind ESPN's coverage (36\% of mentions). Examples included Caitlyn Jenner's ESPY win and the network's coverage of Michael Sam, the first openly gay player selected in the NFL draft. The second most common category was coverage critical of ESPN's staffing decisions, again emphasizing what they revealed about the network's politics (35\% of mentions). This included the firing of baseball analyst Curt Schilling in 2016 after he made anti-transgender comments on social media and ESPN's decision to re-assign announcer Robert Lee, due to the resemblance of his name to the Confederate general, away from a University of Virginia football game in 2017. Finally, 27\% of the articles addressed comments critical of Republicans made by ESPN journalists Jemele Hill, Tony Kornheiser and Cari Champion.

\footnotetext{
${ }^{1}$ The two authors separately evaluated each reference to ESPN in the transcripts to determine if it invoked political considerations when discussing the sports network. We count only those cases in which we agreed. Appendix B.1 discusses this process in detail.
} 
Figure 1: Politicized Mentions of ESPN on Fox News

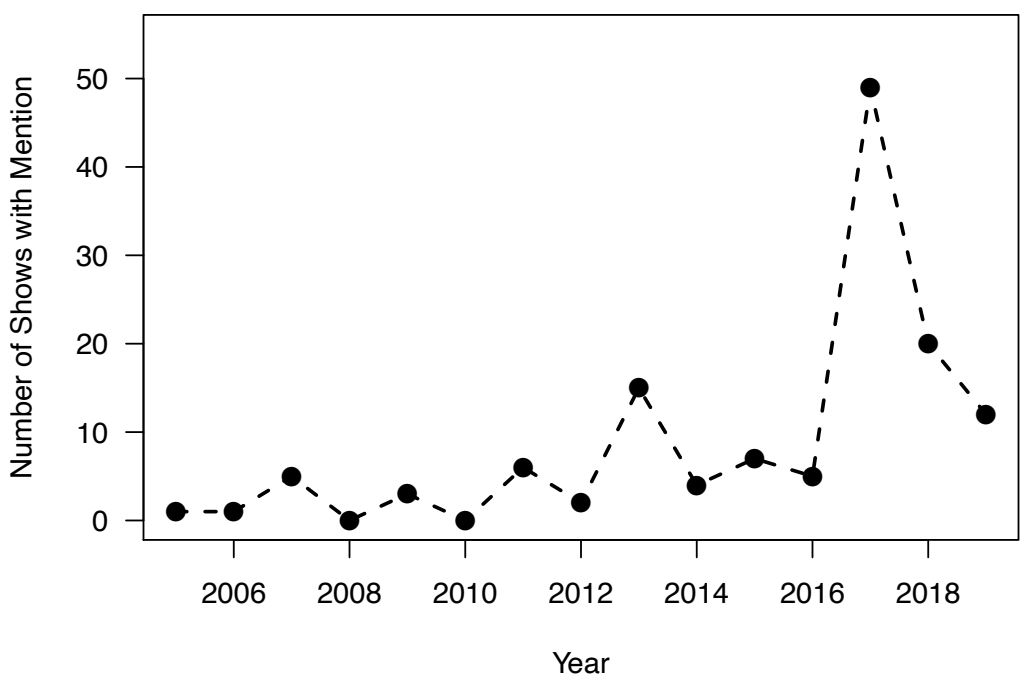

Figure 1 displays the number of times Fox News shows discussed ESPN in a politicized manner each year. This shows a sustained critique of ESPN in recent years that spans many different events. It also establishes political media exposure as a potential vehicle for the politicization of ESPN's overall reputation. Consistent with other work (Serazio 2019, Ch. 5), references that the sports network has delved into politics are not new. Early mentions refer to radio host Rush Limbaugh's short-lived tenure as part of ESPN's NFL coverage in 2003 and discussion in 2013 when ESPN initially refused to air a religious non-profit's advertising. There was a steep uptick in commentary arguing that ESPN possessed a liberal bias in 2017, much of it focusing on Jemele Hill's comments about Trump. Lower, but still elevated, levels of coverage were present in 2018 and 2019, discussing ESPN's re-hiring of MSNBC pundit Keith Olbermann and attributing the network's ratings decline to its political leanings. While Figure 1 focuses on cable television, such commentary was also prevalent on right-leaning online media sources after 2016 (see Appendix B.1).

\section{Assessments of ESPN's Sports Coverage}

Another avenue through which politicization may occur is if the public encounters sports coverage from ESPN, perceives it as political, and changes their view of the network. This pathway most closely resembles the "implicitly political" content Settle (2018) and Lee (ND) 
consider as a way people may perceive political relevance during social interactions.

We consider the prevalence of such coverage by drawing a sample of the most prominent stories on ESPN's website for ten randomly selected days in 2018. Then, following Settle's (2018, Ch. 6) procedure for identifying implicitly political content, we had these 209 articles each assessed by ten coders on Amazon's Mechanical Turk who were asked "In your opinion, is this article about politics?". In a definition we employ throughout the paper, we consider sports news to be politicized if it is perceived to discuss politics by those who encounter it. While subjective, we regard this approach as appropriate here given our focus on how members of the public respond to sports coverage they perceive to be political.

We identified some sports news from ESPN that was perceived as political. This "politicized sports" coverage includes a story where athletes discussed Martin Luther King Jr's "Letter from a Birmingham Jail," an article about the under-representation of minorities in NFL front offices and coverage of a protest by University of Maryland students after football player Jordan McNair's death from heatstroke. Some stories dealt with interactions between sports leagues and government over legalized betting. While such coverage is available, our content analysis shows politicized sports coverage is an infrequent occurrence. It constitutes only $5 \%$ of the stories in the sample, while the remaining $95 \%$ of ESPN's sports stories are not perceived to have political elements. ${ }^{2}$

\section{Data}

Having established two potential channels through which views of ESPN may have been politicized, we now use three studies to consider the origins and consequences of politicized attitudes towards ESPN $\mathrm{S}^{3}$ In Study 1 we examine the association between online media use and assessments of ESPN in a YouGov survey from September $2018(n=1,004)$. This

\footnotetext{
${ }^{2}$ In this content analysis, and a similar one used to select the treatments in Surveys 2 and 3, we consider an article political if three or more coders responded "maybe" or "yes" to the perceived political question. See Appendix B for more information.

${ }^{3}$ See Appendix A for the demographics of each survey.
} 
survey followed the firm's standard procedure of drawing a sample matched to the voting-age population on key demographics. These respondents installed an application that recorded the websites they visited on their computer (see Peterson et al. 2021 for its use in studying political news exposure). We measure exposure to right-leaning political media and visits to ESPN's website. Respondents rated ESPN's trustworthiness. While this does not get at perceptions of the ideological nature of ESPN's coverage, it lets us examine the relationship between partisanship, media use and assessments of the sports network.

Study 2 measures politicized assessments of ESPN. This study was conducted in August 2019 using Lucid ( $\mathrm{n}=5,011$ ). Study 2's sample was drawn using a quota to match the demographics of the U.S. population on race, age and income. Respondents assessed ESPN's reputation using a seven-point scale from one ("Liberal or Pro-Democratic party bias") to four ("No bias at all") to seven ("Conservative or Pro-Republican party bias"). Later, they saw two stories, a sports story from ESPN and a non-sports story from a popular news website, and picked which they preferred to read. This lets us observe the relationship between attitudes towards ESPN and interest in its content.

Finally, we conducted Study 3 in January 2020 using a sample from Qualtrics Panels, quota sampled to match the demographics of the U.S. population $(n=2,000)$. It included an experiment where respondents encountered ESPN's sports coverage or a Fox News story about ESPN. This supplements Study 1 by using randomly assigned media exposure. Views of ESPN were measured with the perceived bias scale from Study 2. Respondents again engaged in news choice tasks to measure interest in ESPN's content.

All three studies measure partisan divides in assessments of ESPN. Study 1 and Study 3 assess how sports and political media exposure influence views of ESPN using both observational and experimental approaches. Finally, Study 2 and Study 3 consider the implications of politicized views of ESPN for use of its sports coverage. 


\section{Partisan Divide in Assessments of ESPN}

We begin by establishing that attitudes towards ESPN are politicized. In Study 1, respondents were told, "We want to know which sources of information you consider more or less trustworthy" and then reported ESPN's trustworthiness on a five-point scale from "not at all trustworthy" to "very trustworthy." We re-code the scale to lie between zero and one, with higher values indicating greater trust 4 In Studies 2 and 3 respondents assessed ESPN's ideological slant on a seven-point scale from very liberal to very conservative. We collapse it into a binary measure of whether or not they perceived ESPN as liberal.

We consider partisan differences in these outcomes. When doing so we include "leaners" with the party they express an affinity towards and leave Independents as only those not leaning towards either party. For now we only consider Survey 3's control group to understand differences that exist without the treatments in that study. Table 1 regresses assessments of ESPN on indicator variables for partisanship. The intercept reflects the views of Democrats, who serve as the reference category. The coefficients for Independents and Republicans represent the difference between these groups and Democrats.

Table 1 provides strong evidence of politicization. In the first survey, there is a sizeable partisan divide in views of ESPN's trustworthiness. The average for Democrats is 0.53, corresponding to roughly the scale's midpoint of "moderately trustworthy." Trust falls by 0.24 points, roughly one-quarter of the scale's width, to 0.29 for Republicans. ESPN is viewed, on average, as only "slightly trustworthy" among this group. Independents fall between the two parties, although they are closer to the views of Republicans.

Studies 2 and 3 asked respondents about the political leaning of ESPN's coverage. Most assessed ESPN as non-partisan by placing it at the mid-point of the scale, indicating the

\footnotetext{
${ }^{4}$ We view this measure as capturing overall sentiment towards the outlet. While we cannot perform this analysis for ESPN, as only the trustworthiness measure was included on the survey, in Appendix E1 we find a strong correlation (0.88) between trustworthiness and feeling thermometer ratings for news outlets where both measures are available.
} 
Table 1: Partisan Divide in Assessments of ESPN

\begin{tabular}{lrrr}
\hline & Trust (Survey 1) & Liberal Bias (Survey 2) & Liberal Bias (Survey 3) \\
\hline (Intercept) & $0.53^{*}$ & $0.20^{*}$ & $0.22^{*}$ \\
& $(0.02)$ & $(0.01)$ & $(0.03)$ \\
Independent & $-0.17^{*}$ & 0.01 & -0.05 \\
& $(0.03)$ & $(0.02)$ & $(0.05)$ \\
Republican & $-0.24^{*}$ & $0.23^{*}$ & $0.11^{*}$ \\
& $(0.03)$ & $(0.01)$ & $(0.04)$ \\
\hline$N$ & 1004 & 5012 & 501 \\
\hline
\end{tabular}

Reference category is Democrats

Robust standard errors in parentheses

* indicates significance at $p<0.05$

network displayed "no bias at all." In Study 2, 58\% of respondents considered the network's coverage to not lean towards either political party, while 29\% considered ESPN liberal and $13 \%$ considered it conservative. Study 3 produced a similar distribution, with $61 \%$ perceiving no bias from ESPN, $25 \%$ perceiving a liberal bias and 14\% perceiving a conservative bias.

Table 1 considers partisan differences in these perceptions, revealing a clear divide in assessments of the sports network's ideology. In the 2019 data, there is a 23 percentage point difference, with more Republicans (43\%) than Democrats (20\%) perceiving ESPN as liberal. In 2020, this partisan difference is 11 percentage points, with $33 \%$ of Republicans perceiving the network as liberal, compared to $22 \%$ of Democrats. In contrast to Survey 1 , the Independents in these studies are closer to Democrats in that they see similar (Survey 2) or lower (Survey 3) levels of liberal bias from ESPN 5

\section{Sources of ESPN's Politicization}

We now turn to the sources of politicized assessments of ESPN. We consider this using an observational study relating online news exposure to attitudes towards ESPN (Survey 1) and a survey experiment that randomly assigns media exposure (Survey 3).

${ }^{5}$ While Table 1 displays unadjusted estimates, these partisan differences remain similar when conditioning on demographics and interest in sports (see Appendix D). 


\section{Online Media Exposure and Assessments of ESPN}

Using Survey 1, we relate views of ESPN to political and sports media use. These respondents were part of YouGov's Pulse panel and had installed a toolbar on their main desktop web browser tracking the websites they visited in the months before the survey ${ }^{6}$

We consider politicization from political media by measuring the partisan slant of a respondent's political news use. We draw on the "alignment scores" of 452 news websites created by Bakshy et al. (2015) which characterize a web domain's political content based on the ideology of those sharing its stories on Facebook. Domains shared more frequently by conservatives received alignment scores closer to one (e.g., Fox News is 0.78) and domains with content more frequently shared by liberals received scores closer to negative one (e.g., Huffington Post is -0.62). We summarize an individual's partisan media exposure by appending a domain's alignment score to every news website visit they made and averaging the alignment of all their visits. For this variable, which we refer to as "Right-Leaning Media Exposure", those with more left-leaning political news exposure receive a negative score, while those with a more right-leaning media diets take a positive value. We expect right-leaning media exposure will be be associated with less trust in ESPN.

We assess whether exposure to ESPN's sports coverage generates politicization with a binary indicator for whether a respondent visited ESPN's website (49\% of the sample had done so). Based on our earlier discussion, evidence ESPN exposure was associated with lower levels of trust would be consistent with politicization through this channel.

When regressing trust in ESPN on political news use and exposure to ESPN's website, we condition on partisanship, demographic measures (i.e., gender, race, age, income and education) and other political variables (i.e., ideology and political interest). These covariates are included as they potentially relate to both online news exposure and trust in ESPN and, if not incorporated, may confound the relationship between media use and views of ESPN. Even with controls, other sources of confounding remain. We later use an experiment to

\footnotetext{
${ }^{6}$ Appendix A contains more information about the web tracking data collection procedure.
} 
address this issue. For now, we proceed with the observational analysis as it presents a valuable opportunity to examine real-world online media use.

Table 2 displays the results of this regression among all respondents (column 1) and separately for Democrats (column 2), Independents (column 3) and Republicans (column 4). Both pooled and sub-group relationships are shown to assess whether they differ by party.7]

Table 2: Trustworthiness of ESPN by Online Media Exposure

\begin{tabular}{lrrrr}
\hline & All & Democrats & Independents & Republicans \\
\hline (Intercept) & $0.47^{*}$ & $0.37^{*}$ & $0.50^{*}$ & -0.01 \\
& $(0.09)$ & $(0.12)$ & $(0.21)$ & $(0.30)$ \\
Right-Leaning Media Exposure & $-0.18^{*}$ & -0.05 & $-0.31^{*}$ & $-0.16^{*}$ \\
& $(0.03)$ & $(0.06)$ & $(0.10)$ & $(0.05)$ \\
ESPN Visitor & $0.04^{*}$ & 0.03 & 0.03 & $0.09^{*}$ \\
& $(0.02)$ & $(0.02)$ & $(0.05)$ & $(0.03)$ \\
\hline$N$ & 926 & 473 & 130 & 323 \\
\hline Models condition on partisanship and demographic variables & & \\
Standard errors in parentheses & & & \\
$*$ indicates significance at $p<0.05$ & & & &
\end{tabular}

The analysis of all respondents (column 1) supports an account in which political media exposure drives politicization. Even after conditioning on demographic and political variables, those with right-leaning political news diets are less trusting of ESPN. Column 1 implies a one standard deviation increase in right-leaning media exposure (0.24) produces an expected $4 \%$ decrease in trust in ESPN. This association between a right-leaning media diet and negative assessments of ESPN is present among all partisan groups, although it is not statistically significant for Democrats and is instead concentrated among Independents and Republicans 8

In contrast, Table 2 offers little evidence that direct experience with ESPN leads to less favorable evaluations. In the pooled sample, the coefficient on ESPN use is positive and statistically significant, indicating those who have experience with ESPN evaluate it four percent more favorably than others. This holds across partisan sub-groups, although

\footnotetext{
${ }^{7}$ Sample sizes are smaller than Table 1 as not all respondents visited political websites.

${ }^{8}$ Appendix Table E3 displays these interactive model results.
} 
it does not remain statistically significant among only Democrats or Independents. The analysis for Republicans is telling, as they are the most likely to react negatively to any perceived politics in ESPN's sports coverage. Instead Republicans who visited ESPN are more favorably disposed towards the sports network $!^{9}$

There are limitations to this observational analysis as, even with controls, we cannot convincingly address all omitted variables that may explain this relationship. We also may have missed negative reactions among those who stopped visiting ESPN before our study began due to their negative reactions to its coverage in the past 10 For this reason, we now turn to a survey experiment.

\section{Experimental Effects of Media Exposure on Views of ESPN}

Survey 3 included an experiment in which respondents were randomly assigned to see news coverage from or about ESPN before assessing the network's ideology. We use this to distinguish the effects of several types of coverage that may generate politicization.117

Two of the treatment categories considered the public's response to different types of sports coverage. One group encountered ESPN's typical coverage and saw an ordinary sports story (e.g., "USWNT set for World Cup semifinal rematch against England"). This offers a chance to see whether even innocuous ESPN coverage provokes any reaction. A second group encountered politicized sports coverage from ESPN, sports news containing elements likely to be perceived as political by those encountering it (e.g., "NFL owners couldn't care less about inclusive hiring, and it shows"). Relative to other sports news, this represents a more likely avenue for coverage to politicize ESPN's reputation.

\footnotetext{
${ }^{9}$ In Appendix Table E2 we report similar findings using different operationalizations of political and sports media exposure.

${ }^{10}$ In Appendix E we see similar patterns when only considering 2016 ESPN exposure.

${ }^{11}$ We select several articles for each treatment category and randomly assign respondents to see one of them, ensuring the effect of a treatment category does not hinge on idiosyncratic features of a single article (see Appendix C for information on these articles).
} 
To ensure the stories in these categories were perceived in the intended manner, we selected them using a pre-test that resembled the content analysis presented earlier in this paper. A set of 28 candidate articles drawn from ESPN's website were each evaluated by 20 coders on Amazon's Mechanical Turk who were asked to assess whether they discussed politics (see Appendix C3 for detail). The articles used in the sports treatment were not perceived to have political content $(0 \%$ of coders evaluated articles in this category as discussing politics), while the articles used in the politicized sports treatment were broadly perceived to discuss politics $(67 \%$ of coders evaluated articles in this category as having political content) and generally seen to have a liberal political slant. The stories in the politicized sports category are intentionally strong operationalizations of this treatment. They touch on areas perceived as "implicitly political" in previous work (e.g., Settle 2018), in particular how issues of race, gender and sexual orientation intersect with the sports world, they are perceived as containing a liberal bias in the experimental pre-test (see Appendix Table C4) and, finally, they align with the sports coverage right-leaning media emphasize in their critiques of ESPN.

In addition to sports coverage, a third treatment group saw a political news article from Fox News (e.g., "ESPN reminds staffers to stick to sports, not talk politics after star rips Trump on-air"), operationalizing the channel in which political media exposure alters views of the sports network. Finally, the control group proceeded to the outcome without encountering an article, providing a baseline for evaluations without the treatments. The outcome in the experiment is whether or not respondents perceived ESPN as liberal.

In Table 3, we regress perceptions of ESPN's ideology on indicators for each treatment category. This compares the difference between each treatment group and the control ${ }^{12}$ As before, we examine pooled results for the entire sample (column 1), and look at effects among partisan sub-groups to assess effect heterogeneity (columns 2-4).

${ }^{12} \mathrm{~A}$ balance test in Appendix Table A3 reveals no significant covariate imbalance between those randomly assigned to different treatment conditions. 
Table 3: Effects of Media Exposure on Perception of ESPN as Liberal

\begin{tabular}{lcccc}
\hline & All & Democrats & Independents & Republicans \\
\hline (Intercept) & $0.25^{*}$ & $0.22^{*}$ & $0.17^{*}$ & $0.33^{*}$ \\
& $(0.02)$ & $(0.03)$ & $(0.04)$ & $(0.04)$ \\
Sports & 0.01 & 0.03 & -0.02 & 0.00 \\
& $(0.03)$ & $(0.04)$ & $(0.06)$ & $(0.05)$ \\
Politicized Sports & $0.06^{*}$ & 0.04 & 0.06 & 0.08 \\
& $(0.03)$ & $(0.04)$ & $(0.07)$ & $(0.05)$ \\
Political News & $0.11^{*}$ & $0.12^{*}$ & 0.05 & $0.12^{*}$ \\
& $(0.03)$ & $(0.04)$ & $(0.07)$ & $(0.05)$ \\
\hline$N$ & 2000 & 1020 & 272 & 708 \\
\hline Robust standard errors in parentheses \\
$*$ indicates significance at $p<0.05$
\end{tabular}

Table 3 offers no indication ESPN's typical sports coverage contributes to politicization. In the full sample, the difference in assessments of ESPN's ideology between those encountering sports coverage and the control group was small (1 percentage point, $95 \%$ Confidence Interval $[-0.04,0.07])$ and not statistically significant. Similar patterns occur among each partisan sub-group. This non-political sports coverage, which constituted $95 \%$ of the coverage available from ESPN online in our earlier content analysis, does not produce politicization.

Next, there is evidence exposure to sports coverage incorporating social and political issues increased assessments of ESPN as liberal. In the pooled sample, those who encountered politicized sports coverage were 6 percentage points more likely (95\% Confidence Interval $[0.01,0.12])$ to consider ESPN liberal than the control group. This estimate's magnitude is similar across partisan sub-groups, indicating the absence of substantial heterogeneity in response to the coverage, although these effects are no longer statistically significant when separately considering partisans. This provides evidence that some aspects of sports news can generate politicized responses from the public.

Finally, exposure to political news substantially increased politicized assessments of ESPN. Those in the political treatment group were 11 percentage points more likely than the control to assess ESPN as liberal. This is nearly double the effect of exposure to politicized sports news, although it is important to note the difference between the political news and politicized sports treatment effects $(0.05,95 \%$ Confidence Interval $[-0.01,0.11])$ is not 
detectable at the level of significance we use throughout the paper. Again, looking across groups of partisans, there is limited variation in the effects among Democrats and Republicans. The other columns of the table indicate a lack of substantial heterogeneity in these effects by party. For Independents, the point estimate is smaller and no longer significant, though still positive. Should they encounter it, right-leaning political media coverage politicizes attitudes towards ESPN, even among Democrats. ${ }^{13}$

Altogether, there are three key findings from our examination of the sources of politicization. First, observational and experimental evidence shows the influence of political elites extends into assessments of a sports network. Second, ESPN's typical sports coverage did not politicize assessments of the network. When paired with our content analysis, this indicates the vast majority of the sports news available from ESPN did not contribute to politicizing its reputation. Third, in the survey experiment we find that encountering politicized sports coverage made respondents more likely to view ESPN as liberal. Given the small share of ESPN's coverage of this type in our content analysis, and the absence of politicization from ESPN exposure in the observational study, we conclude this channel contributes less than partisan media use to politicization.

\section{Consequences of ESPN's Politicization}

To assess the consequences of politicization, we now examine the relationship between politicized attitudes towards ESPN and interest in its coverage. We first consider Surveys 2 and 3. After measuring perceptions of ESPN's slant, respondents engaged in news choice tasks. They were presented with pairs of headlines and indicated which they preferred to read. The pairing contrasted a sports article from ESPN with a randomly selected nonsports story from one of several popular online news sources. In Survey 2, ESPN's sports story did not have any political elements. In the four choice tasks in Survey 3, respondents saw two non-political sports stories, but also encountered two politicized sports headlines.

${ }^{13}$ We formally test for heterogeneity by party with an interaction model in Appendix E and do not see statistically significant differences in treatment effects by party. 
The politicized sports headlines were identified with the same pre-testing procedure used to select experimental treatments in the previous section (see Appendix C.2), and again differed from other sports coverage in that they were perceived to contain political content.

We assess the relationship between perceptions of ESPN and interest in its content by combining Surveys 2 and 3 and examining 12,632 decisions between ESPN's sports coverage and an alternative. We regress an indicator for whether a respondent selected ESPN on their partisanship, their perception of ESPN's ideological slant and their interest in sports, an apolitical concern that may factor into their news choice (e.g., Mummolo 2016) 14 Survey 3 respondents made several choices, so we cluster standard errors by respondent.

Table 4 analyzes ESPN selection. The first column displays the results using all news choice tasks. The second column displays this for non-political sports news from ESPN. The third column displays this for decisions that involved politicized sports news from ESPN.

Table 4: $\operatorname{Pr}($ Select ESPN) by Party, Content Perceptions and Interests

\begin{tabular}{lccc}
\hline & All & Sports Only & Politicized Sports Only \\
\hline (Intercept) & $0.33^{*}$ & $0.29^{*}$ & $0.44^{*}$ \\
& $(0.03)$ & $(0.04)$ & $(0.06)$ \\
Independent & 0.00 & 0.01 & -0.01 \\
& $(0.01)$ & $(0.02)$ & $(0.03)$ \\
Republican & $0.02^{*}$ & $0.06^{*}$ & $-0.06^{*}$ \\
& $(0.01)$ & $(0.01)$ & $(0.02)$ \\
Perceive ESPN as Liberal & 0.01 & 0.02 & -0.01 \\
& $(0.01)$ & $(0.01)$ & $(0.02)$ \\
Sports Fan & $0.22^{*}$ & $0.25^{*}$ & $0.16^{*}$ \\
& $(0.01)$ & $(0.02)$ & $(0.02)$ \\
\hline$N$ & 12632 & 8816 & 3816 \\
\hline Models also condition on demographic variables & \\
Robust standard errors, clustered by Respondent, in parentheses \\
$*$ indicates significance at $p<0.05$
\end{tabular}

The first column of Table 1 indicates Republicans were 2 percentage points more likely than Democrats to select ESPN. The partisan difference is small and runs against the ex-

\footnotetext{
${ }^{14}$ To measure sports interest, respondents indicated their primary interest among nine non-political areas of online news. These were: Arts and Culture, Business, Entertainment News, Health and Wellness, Science, Sports, Style, Tech News and Travel.
} 
pectation ESPN use would tilt towards Democrats. There is no evidence of a relationship between politicized attitudes towards ESPN and interest in its content, as the point estimate is small and not distinguishable from zero $(0.01,95 \%$ Confidence Interval $[-0.01,0.02])$. Finally, the key determinant of choice to emerge is sports fandom, as those interested in sports were 22 percentage points more likely than others to select an ESPN article 15

When separating different types of sports coverage in columns 2 and 3 of Table 4, interest in sports again emerges as the primary predictor of ESPN use. Similarly, politicized evaluations of ESPN do not have a relationship with selecting its content in either case. There is one important distinction between the different coverage types. Republicans are six percentage points more likely than Democrats to select the non-political sports coverage from ESPN, but this difference flips when turning to the politicized sports coverage, as Republicans became less likely than Democrats to select politicized sports stories (-.06, 95\% Confidence Interval [-.08, -.04]). This speaks to the relative unpopularity of politicized sports coverage among all Republicans, whether or not they hold politicized views of ESPN.

Table 4 shows interest in sports is more predictive of selecting ESPN's content than political factors. However, this could mask heterogeneity in the implications of politicized assessments. Republicans, in particular, may be less interested in ESPN's coverage when they perceive the network as liberal. Accordingly, we separately examine the relationship between politicized attitudes and choice among each partisan group in Figure 2.

\footnotetext{
${ }^{15}$ Appendix Figure F1 shows results are similar when we separate out each choice task based on which political media source was available as an alternative.
} 
Figure 2: Politicized Attitudes and ESPN Selection in News Choice Tasks

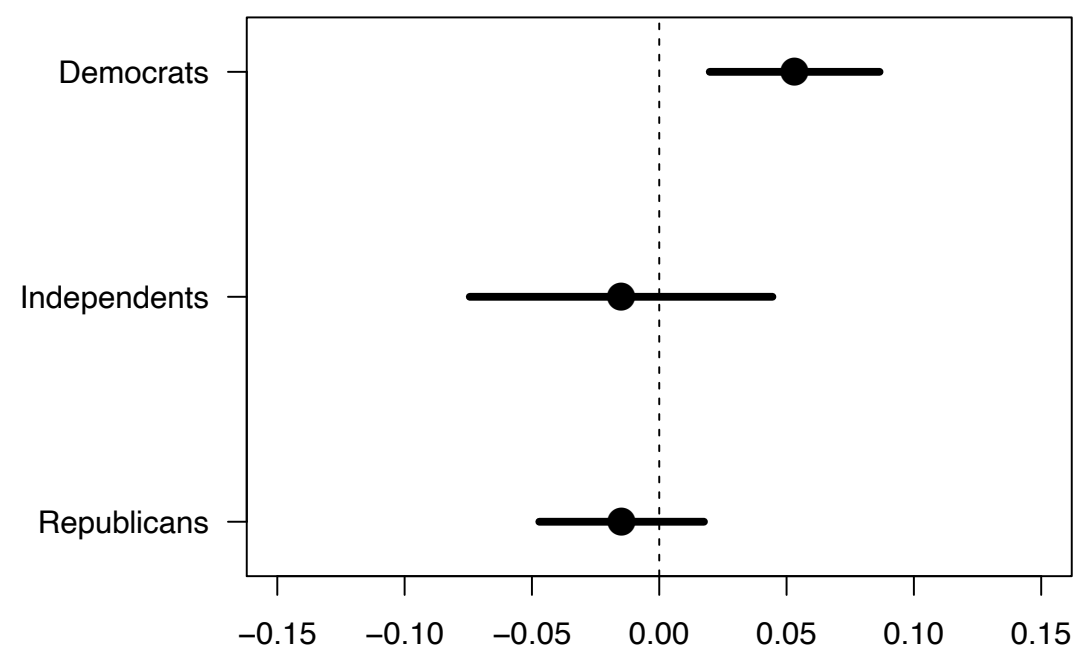

Marginal Difference in Choice from Perceiving Liberal Bias at ESPN

Looking separately by partisan group, Figure 2 offers limited evidence politicized attitudes towards ESPN generate avoidance. For Democrats, holding politicized attitudes produced a 5 percentage point increase in the probability of selecting it (95\% Confidence Interval $[0.02,0.09])$. Among Republicans (-0.02, 95\% Confidence Interval [-0.05, 0.02]) and Independents $(-0.02,95 \%$ Confidence Interval $[-0.07,0.4])$ there is a small negative relationship between holding politicized views of ESPN and selecting its content, but the association is not distinguishable from zero.

\section{Exposure to ESPN's Website}

The news choice tasks in the surveys allow us to precisely measure interest in different types of content from ESPN, but constrain media consumption compared to the real-world by forcing a choice between story pairs. To conclude, we consider partisan divides in ESPN use outside the surveys by revisiting the web-tracking data from Survey 1.

We operationalize ESPN use in three ways. First, we create a binary measure of whether a respondent visited ESPN's website (49\% of respondents had done so). Second, we create a continuous measure, the average number of pages a respondent visited on ESPN's website 
on days their toolbar was active (the average was 0.3 daily visits) ${ }^{16}$ Third, to account for the possibility ESPN's politicization led some to defect to other sports websites, we consider the difference between the average number of daily visits made to ESPN and the average number of daily visits made to sports websites that are alternatives to ESPN.17 For the differenced outcome (i.e., the difference between average daily visits to ESPN and average daily visits to other sports websites), higher values indicate greater reliance on ESPN than other sports sources. ESPN was the most popular website in the group, receiving $45 \%$ of all the visits to these sports outlets, so the average of the difference measure is negative as the combined set of other websites received more web traffic than ESPN on its own.

Table 5 considers differences in ESPN use by partisanship. Across the measures, partisan divides are small and do not reach statistical significance. Republicans were as likely as others to visit ESPN, on both the binary and continuous operationalizations of sports news use, and did not seek out alternative sources of sports news at higher rates than others.

Table 5: Visits to ESPN's Website by Party

\begin{tabular}{lccc}
\hline & Binary & Continuous & Difference \\
\hline (Intercept) & $0.48^{*}$ & $0.25^{*}$ & -0.08 \\
& $(0.02)$ & $(0.04)$ & $(0.05)$ \\
Independent & 0.02 & 0.07 & 0.04 \\
& $(0.05)$ & $(0.09)$ & $(0.11)$ \\
Republican & -0.01 & 0.04 & 0.05 \\
& $(0.04)$ & $(0.07)$ & $(0.08)$ \\
\hline$N$ & 962 & 962 & 962 \\
\hline
\end{tabular}

Robust standard errors in parentheses

* indicates significance at $p<0.05$

This pattern of sports news use is relatively stable over time. In Figure 3, we consider the difference in average daily visits between Republicans and Democrats, estimated separately

${ }^{16}$ There are some outliers (e.g., the most frequent visitor saw an average of over 60 pages on ESPN per day). To pull in these outliers, we re-code extreme values that exceed the 97.5 percentile of the visit distribution to the value at that point (5.2).

17 These other websites are seven high-traffic alternatives to ESPN: Yahoo Sports, Bleacher Report, CBS Sports, NBC Sports, SB Nation, Sports Illustrated and Fox Sports. 
each month from August 2016 to March 2018. This is possible because we observed web traffic data over this entire period for 446 respondents who were part of a long-term panel 18

Figure 3: Partisan Difference in Average Daily Visits to ESPN's Website by Month

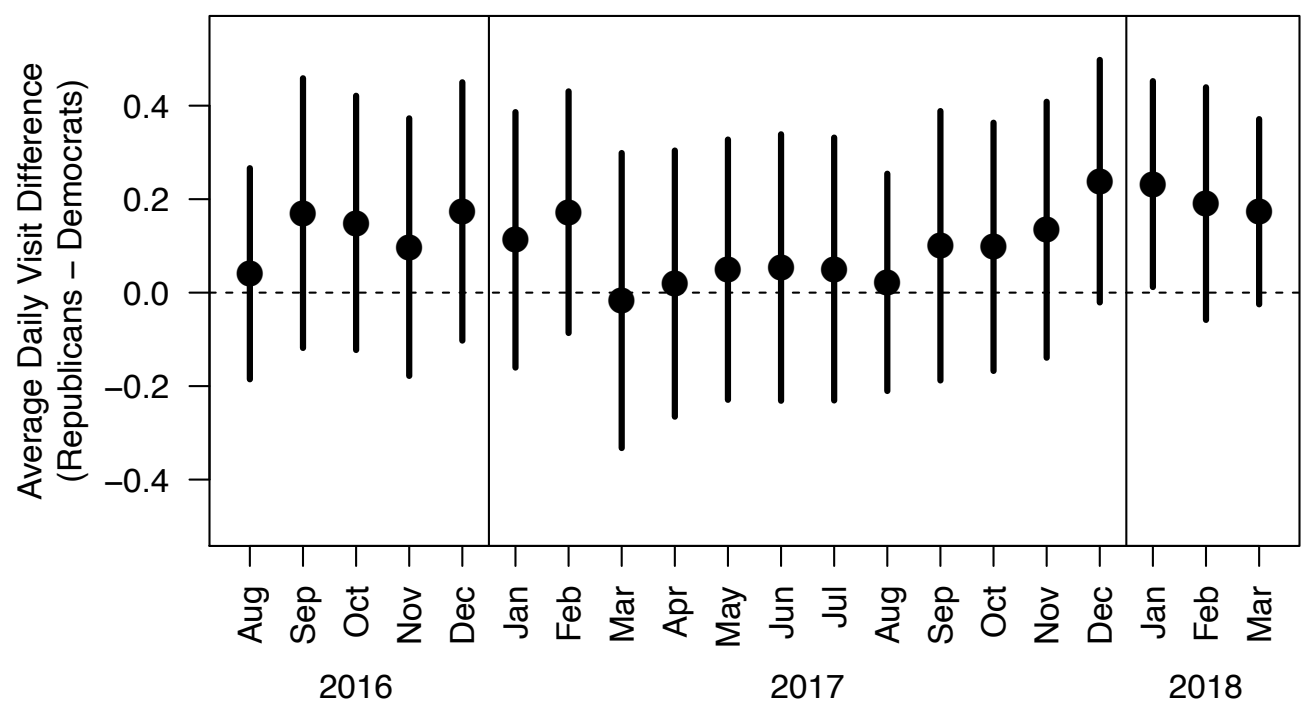

Figure 3 shows the difference in average daily visits is generally positive, indicating Republicans visited ESPN's website slightly more than Democrats, although the difference fails to reach statistical significance. Like Table 5, this monthly assessment offers no indication of Republican avoidance of ESPN or any trend towards greater partisan behavioral differences. As we lack a reference for how these divides appeared before August 2016, we cannot rule out changes in partisan sports news consumption changed compared to earlier periods. However, it is relevant that we do not observe much change in the relationship between partisanship and sports news use over this window, in particular greater avoidance of ESPN by Republicans, as it spans a major politicizing event-Jemele Hill's comments about Donald Trump in September 2017-which leaves no impression on partisan divides in use.

Our consideration of the consequences of ESPN's politicization for sports media consumption shows limited behavioral implications for the attitudinal divides revealed in earlier sections. When assessing survey-based news choice, politicized views of ESPN did not pro-

${ }^{18}$ Measured browsing activity of the long-term panelists declined after March 2018 due to increased non-compliance with the toolbar, so we omit consideration of later months. 
duce avoidance. In the web browsing data, we find no partisan differences in visits to ESPN's website among the same sample where a large partisan divide existed in attitudes towards the sports network. In summarizing our findings, it is important to mention our analysis cannot rule out other potential behavioral impacts of ESPN's politicized reputation and future work remains needed in some important areas. While we see no falloff in overall engagement with ESPN, more subtle changes in sports news consumption at the article or program level could have occurred. Relatedly, the politicization of views of ESPN may have more delayed or broader consequences for how respondents engaged with entertainment media in general, perhaps becoming one element of social sorting occurring at a gradual pace over a longer time horizon.

\section{Discussion and Conclusion}

At times sports provides a unique setting that can cut through political and social divides (e.g., Alrababa'h et al. 2021). In other instances sports simply reflect or amplify conflicts that exist elsewhere in society (e.g., Serazio and Thorson 2020). Our mixed evidence touches on both qualities as we find political considerations are relevant for evaluating a major sports media outlet, an extension of partisan divisions into social life, but also observe this does not manifest in differences in behavior.

Although we examine politicization in the context of sports, our findings have implications for understanding the sources of the extension of political divides into social life more generally. In contrast to studies which demonstrate it due to researcher-provided political cues, our evidence supports the notion that exposure to messages from political media can politicize attitudes in these domains. While we did not find as much support for it here, people's own experiences with some previously non-political entity may be a more plausible source of politicized evaluations in other contexts where such interactions are more routinely perceived to have some degree of political relevance.

We again note that our focus here is on a case of asymmetric polarization, with rightleaning media attacking a sports network as liberal. While future work is needed, we do 
see the avenues of politicization we consider here as also applicable to situations in which left-leaning political media are instead the crucial actors. The political consumerism literature identifies some candidate cases for future research where the sources of politicization we consider here are plausible and could be linked to consumer behavior, for instance the politicization of the restaurant Chick-fil-A's reputation after revelations of political donations to conservative causes by its owners (e.g., Settle 2018).

With respect to studies of elite influence, our finding that political media exposure can shape perceptions of a sports network provides an important extension of previous findings regarding the influence of political elites (see also Endres et al. 2021). To the extent political media and politicians direct rhetoric towards an apolitical entity, their influence can extend beyond politics. This points to the importance of future work examining when and why politicians and partisan media attempt to introduce politics into formerly apolitical settings. As we consider media outlet reputations, our framework is also helpful for studying the origins of hostile attitudes towards political news media and our evidence aligns with other accounts about the role of attacks from political elites, more so than any negative responses to news coverage itself, in generating antipathy towards the media (Ladd 2010, Archer 2020, Peterson and Kagalwala 2021).

The minimal role of these newly politicized attitudes in sports news use speaks to a recent theme in studies of elite influence. Zaller $(2012,571)$ notes partisans "give little weight to their leadership-induced opinions when it comes time to make political choices. They parrot the party line, but do not vote it." While the outcome we consider is not a policy attitude or voting decision, our findings are consistent with such limits on elite influence.

In explaining the limited behavioral implications of politicized attitudes in this case, we see two factors as particularly relevant in blunting the impact of ESPN's politicized reputation on sports news use. First, sports fandom is an important identity for many (e.g., Thorson and Serazio 2019, Engelhardt and Utych 2020, Alrababa'h et al. 2021) and the public's entertainment media habits were formed prior to the critiques of ESPN on political 
media. These features of the case we study may have lent sports fandom sufficient relevance to offset an individual's political affiliations when the two considerations conflicted. Second, our content analysis revealed that, in the coverage typically produced by ESPN, only a limited amount of its sports coverage was perceived by members of the public to be infused with politics. This lack of repeated, salient examples of politicized sports news for those actually encountering ESPN's coverage also seems relevant in explaining why attitudinal divides towards the sports network did not subsequently manifest in terms of people's overall engagement with ESPN's coverage. While future work on these topics is needed, we anticipate the carryover of partisan attitudinal divides into behavior is more likely to occur in situations where firm habits were not in place before politicization occurred and where the salience of politicized encounters was more frequent than what we found here.

Ultimately, this disconnect between partisan divides in attitudes and behavior we observe is relevant to studies of affective polarization and political consumerism and suggests a direction for future research on this topic. While there is plenty of evidence that partisan attitudinal differences can shape meaningful behaviors (Iyengar and Westwood 2015, McConnell et al. 2018, Panagopoulos et al. 2020), our study sits with some others in identifying situations where such translation from attitudes to behavior does not happen (Mummolo and Nall 2017, McGrath 2017). This reinforces the need to link political attitudes with measures of behavior when possible and, if not, to take appropriate caution when extrapolating the behavioral implications of partisan differences from attitudes alone. In line with our preceding discussion, this also emphasizes the need for research synthesizing these mixed findings into a clearer set of expectations about when the apparent intrusion of politics into apolitical aspects of everyday life does and does not spill into behavior. 


\section{References}

Alrababa'h, Ala', William Marble, Salma Mousa and Alexandra Siegel. 2021. "Can Exposure to Celebrities Reduce Prejudice?" American Political Science Review 115(4): 11111128.

Andreeva, Nellie and Ted Johnson. 2019. "Cable Ratings 2019." Deadline. https:// deadline.com/2019/12/cable-ratings-2019-list-fox-news-total-viewers-espn-1849-demo-1202817561/. Accessed April 22, 2020.

Archer, Allison. 2020. "Attacking the Fourth Estate: The Nature and Effects of Political Leaders' War with the Press." In Leadership, Populism and Resistance (Eds. Krisitin M.S. Bezio and Al Goethals). Edward Elgar.

Bakshy, Eytan, Solomon Messing and Lada A. Adamic. 2015. "Exposure to Ideologically Diverse News and Opinion on Facebook." Science 348(6239): 1130-1132.

Brody, Richard A. and Paul M. Sniderman. 1977. "From Life Space to Polling Place." British Journal of Political Science 7(3): 337-360.

Carlson, Taylor N. and Jamie E. Settle. 2016. "Political Chameleons: An Exploration of Conformity in Political Discussions." Political Behavior 38(4): 817-859.

Clavio, Galen and Ryan Vooris. 2018. "ESPN and the Hostile Media Effect." Communication Es Sport 6(6): 728-744.

DellaPosta, Daniel, Yongren Shi and Michael Macy. 2015. "Why Do Liberals Drink Lattes?" American Journal of Sociology 120(5): 1473-1511.

Endres, Kyle, Costas Panagopoulos and Donald P. Green. 2021. "Elite Messaging and Partisan Consumerism." Political Research Quarterly 74(4): 834-851.

Endres, Kyle and Costas Panagopoulos. 2017. "Boycotts, Buycotts, and Political Consumerism in America." Research \& Politics 4(4): 1-9.

Engelhardt, Andrew M. and Stephen M. Utych. 2020. "Grand Old (Tailgate) Party? Partisan Discrimination in Apolitical Settings." Political Behavior 42(4): 769-789.

Falcous, Mark, Matthew G. Hawzen and Joshua I. Newman. 2019. "Hyperpartisan Sports 
Media in Trump's America." Communication ES Sport 7(5): 586-610.

Fitzgerald, Jennifer. 2013. "What Does 'Political' Mean to You?" Political Behavior 35(3): 453-479.

Hetherington, Marc and Jonathan Weiler. 2018. Prius or Pickup? Houston Mifflin Harcourt. Hiaeshutter-Rice, Dan, Fabian G. Neuner and Stuart Soroka. ND. "Cued by Culture: Political Imagery and Partisan Evaluations." Political Behavior Forthcoming.

Hiebert, Paul. 2017. "Conservatives seem to be turning away from ESPN." https://today. yougov.com/topics/sports/articles-reports/2017/05/03/Conservatives-seem-tobe-turning-away-from-ESPN Accessed April 22, 2020.

Huber, Gregory A. and Neil Malhotra. 2017. "Political Homophily in Social Relationships: Evidence from Online Dating Behavior." Journal of Politics 79(1): 269-283.

Iyengar, Shanto and Sean Westwood. 2015. "Fear and Loathing Across Party Lines: New Evidence on Group Polarization." American Journal of Political Science 59(3): 690-707. Iyengar, Shanto, Yphtach Lelkes, Matthew Levendusky, Neil Malhotra and Sean J. Westwood. 2019. "The Origins and Consequences of Affective Polarization in the United States." Annual Review of Political Science 22, 129-146.

Kam, Cindy D. and Maggie A. Deichert. 2020. "Boycotting, Buycotting, and the Psychology of Political Consumerism." Journal of Politics 82(1): 72-88.

Kim, Eunji. ND. "Entertaining Beliefs in Economic Mobility." American Journal of Political Science Forthcoming.

Krupenkin, Masha. 2021. "Does Partisanship Affect Compliance with Government Recommendations?" Political Behavior 43(1): 451-472.

Ladd, Jonathan. 2010. "The Neglected Power of Elite Opinion Leadership to Produce Antipathy Toward the News Media: Evidence from. Survey Experiment." Political Behavior $32(1): 29-50$.

Lee, Amber Hye-Yon. 2021. "How the Politicization of Everyday Activities Affects the Public Sphere: The Effects of Partisan Stereotypes on Cross-Cutting Interactions." Political 
Communication 38(5): 499-518.

Levendusky, Matthew. 2013. How Partisan Media Polarize America. University of Chicago Press.

Margolis, Michele F. 2017. "How Politics Affects Religion: Partisanship, Socialization, and Religiosity in America." Journal of Politics 80(1): 30-43.

Mason, Lilliana. 2018. Uncivil Agreement: How Political Became Our Identity. University of Chicago Press.

McConnell, Christopher, Yotam Margalit, Neil Malhotra and Matthew Levendusky. 2018. "The Economic Consequences of Partisanship in a Polarized Era." American Journal of Political Science 62(1): 5-18.

McGrath, Mary C. 2017. "Economic Behavior and the Partisan Perceptual Screen." Quarterly Journal of Political Science 11(4): 363-383.

Miller, James Andrew and Tom Shales. 2011. Those Guys Have All The Fun: Inside the World of ESPN. Little, Brown and Company.

Mummolo, Jonathan. 2016. "News from the Other Side: How Topic Relevance Limits the Prevalence of Partisan Selective Exposure." Journal of Politics 78(3), 763-773.

Mummolo, Jonathan and Clayton Nall. 2017. "Why Partisans Do Not Sort: The Constraints on Political Segregation." Journal of Politics 79(1): 45-59.

Newman, Benjamin and Brandon Bartels. 2011. "Politics at the Checkout Line." Political Research Quarterly 64(4): 803-817.

Panagopoulos, Costas, Donald P. Green, Jonathan Krasno, Michael Schwam-Baird and Kyle Endres. 2020. "Partisan Consumerism: Experimental Tests of Consumer Reactions to Corporate Political Activity." Journal of Politics 82(3): 996-1007.

Peterson, Erik and Ali Kagalwala. 2021. "When Unfamiliarity Breeds Contempt: How Partisan Selective Exposure Sustains Oppositional Media Hostility." American Political Science Review 115(2): 585-598.

Peterson, Erik, Sharad Goel and Shanto Iyengar. 2021. "Partisan Selective Exposure in 
Online News Consumption: Evidence from the 2016 Presidential Campaign." Political Science Research 65 Methods 9(2): 242-258.

Ramachandran, Shalini. 2018. "Adding to ESPN's Struggles: Politics." Wall Street Journal A1, May 25, 2018.

Serazio, Michael. 2019. The Power of Sports. New York University Press.

Serazio, Michael and Emily Thorson. 2020. "Weaponized Patriotism and Racial Subtext in Kaepernick's Aftermath." Television \& New Media 21(2): 151-168.

Settle, Jaime E. 2018. Frenemies: How Social Media Polarizes America. Cambridge University Press.

Settle, Jaime E. and Taylor N. Carlson. 2019. "Opting Out of Political Discussions." Political Communication 36(3): 476-496.

Shafranek, Richard M. 2021. "Political Considerations in Nonpolitical Decisions: A Conjoint Analysis of Roommate Choice." Political Behavior 43(1): 271-300.

Shah, Dhavan V., Douglas M. McLeod, Eunkyung Kim, Sun Young Lee, Melissa R. Gotlieb, Shirley S. Ho and Hilde Breivik. 2007. "Political Consumerism." ANNALS of the American Academy of Political and Social Science 611(1): 217-235.

Smith, Lucas. 2019. "Fun in the Sun: Comscore Rankings Show July Growth from '18" Sports Business Daily. https://www.sportsbusinessdaily.com/Daily/Issues/2019/ 08/16/Media/Comscore.aspx. Accessed April 22, 2020.

Strauss, Ben. 2017. "Did Too Much Caitlyn Jenner Doom ESPN?" Politico May 2, 2017. https://www.politico.com/magazine/story/2017/05/02/did-too-much-caitlyn-jennerdoom-espn-215093

Thorson, Emily A. and Michael Serazio. 2018. "Sports Fandom and Political Attitudes." Public Opinion Quarterly 82(2): 391-403.

Traina, Jimmy. 2019. "Dan Le Batard Calls Out ESPNs 'No Politics' Policy as 'Weak,' 'Cowardly'" Sports Illustrated https://www.si.com/extra-mustard/2019/07/19/danle-batard-espn-no-politics-policy-weak-cowardly-donald-trump 
Towler, Christopher C., Nyron N. Crawford and Robert A. Bennett, III. 2020. "Shut Up and Play: Black Athletes, Protest Politics and Black Political Action." Perspectives on Politics 18(1): 111-127.

YouGov. 2017. "Daily Survey Results." https://today.yougov.com/topics/media/surveyresults/daily/2017/09/18/3dba4/1 Accessed April 22, 2020.

Zaller, John R. 2012. "What Nature and Origins Leaves Out." Critical Review 24(4): 569642. 
Supporting Information for: " 'Stick to Sports': Evidence from Sports Media on the Origins and Consequences of Newly Politicized Attitudes" 


\section{Contents}

\begin{tabular}{ll}
\hline A Appendix A: Survey Information & 1
\end{tabular}

A.1 Sample Composition . . . . . . . . . . . . . . . . . . . . . . 1

A.2 Web Tracking Data . . . . . . . . . . . . . . . . . . . . . . . . . 1

A.3 Balance Test in Survey 3 . . . . . . . . . . . . . . . . . . . . 2

\begin{tabular}{ll}
\hline B Appendix B: Content Analysis & 4
\end{tabular}

B.1 Political Media Portrayals of ESPN . . . . . . . . . . . . . . . . . . . . 4

B.2 ESPN Sports Coverage . . . . . . . . . . . . . . . . . . 5

\begin{tabular}{ll|l|}
\hline C & Appendix C: Materials for Experimental Treatments & 7
\end{tabular}

C.1 News Exposure Treatments . . . . . . . . . . . . . . . . . . 7

C.2 Content in News Choice Tasks . . . . . . . . . . . . . . . . 7

C.3 Coder Assessments of Survey 3 Sports Content . . . . . . . . . . . . . . . . 10

D Appendix D: Supplementary Analyses - Partisan Divide in Views of ESPN 12

\begin{tabular}{lll}
\hline E Appendix E: Supplementary Analyses - Sources of Politicization & 14
\end{tabular}

E.1 Relationship Between Media Outlet Trustworthiness and Sentiment (Survey 1) 14

E.2 Alternative Measures of Political and Sports Media Exposure (Survey 1) . . 15

E.3 Political News Exposure by PID Interactions (Survey 1) $\ldots \ldots \ldots$

E.4 2016 Sports News Exposure (Survey 1) . . . . . . . . . . . . . . . . 17

E.5 Treatment by PID Interactions (Survey 3 ) $\ldots \ldots \ldots \ldots$

E.6 Alternative Outcome in Survey Experiment (Survey 3) . . . . . . . . . . . 20

\begin{tabular}{|lll}
\hline F & Appendix F: Supplementary Analyses - News Choice & 21
\end{tabular}

F.1 Effects of Experimental Treatments on Sports News Choice . . . . . . . . . . 21

F.2 $\quad$ ESPN Choice by Alternative . . . . . . . . . . . . . . . . . . . . . 21

F.3 Indicators of Sports News Choice Over Time . . . . . . . . . . . . . . . . . 22 


\section{A Appendix A: Survey Information}

\section{A.1 Sample Composition}

Table A1 displays the demographic characteristics of the three surveys. We use sampling weights when considering the demographics of Survey 1, which were provided by YouGov. Survey 2 and Survey 3 used quota sampling to align the sample with representative characteristics of the U.S. population.

Table A1: Demographics by Survey

\begin{tabular}{rlll}
\hline Survey & Survey 1 & Survey 2 & Survey 3 \\
\hline Black & 0.11 & 0.11 & 0.12 \\
Hispanic & 0.09 & 0.07 & 0.12 \\
White & 0.73 & 0.69 & 0.62 \\
Other Race & 0.07 & 0.13 & 0.15 \\
College & 0.38 & 0.32 & 0.36 \\
Female & 0.54 & 0.52 & 0.51 \\
Age & 51.01 & 45.08 & 42.57 \\
Democrat & 0.51 & 0.46 & 0.51 \\
Republican & 0.35 & 0.39 & 0.35 \\
Independent & 0.14 & 0.15 & 0.14 \\
\hline Sample Size & 1004 & 5030 & 2000 \\
\hline
\end{tabular}

\section{A.2 Web Tracking Data}

We observe web tracking data for $95 \%$ of the Survey 1 respondents who had agreed to install an online toolbar on their primary desktop web browser. When active, this toolbar tracked the individual urls they encountered while browsing the internet. Respondents were able to turn the toolbar on and off as they wished, but received incentives for keeping it active. We use 1) counts of their visits to either espn. com or espn.go.com to characterize whether they directly encountered ESPN's content and 2) to, assess politicization from exposure to political media, counts of the number of times they visited 452 news websites that were assigned an alignment score by Bakshy et al. (2015) and average the visit-weighted alignment score of all of a respondent's web traffic preceding the survey (the window of time we observe 
their web traffic varies by participant based on how long they remained active in using the toolbar) to characterize their news choices outside of the survey context.

Table A2 displays the demographics (unweighted) of the web traffic sample for Survey 1. It separately displays demographics for the subset of respondents in the long-term panel, which we analyze in Figure 2 of the main text.

Table A2: Survey Demographics with Web Traffic

\begin{tabular}{rll}
\hline Survey & Panel & Survey 1 w/ Web Traffic \\
\hline Black & 0.06 & 0.06 \\
Hispanic & 0.04 & 0.05 \\
White & 0.85 & 0.82 \\
Other Race & 0.05 & 0.07 \\
College & 0.46 & 0.43 \\
Female & 0.51 & 0.50 \\
Age & 58.63 & 58.13 \\
Democrat & 0.54 & 0.51 \\
Republican & 0.33 & 0.35 \\
Independent & 0.12 & 0.14 \\
\hline Sample Size & 446 & 949 \\
\hline
\end{tabular}

\section{A.3 Balance Test in Survey 3}

We also consider the balance across the different experimental conditions in Survey 3. We regress an indicator for the various treatment conditions, ( 1 if in treatment, 0 if in control) for each treatment-control pairing in the study, on a battery of demographic variables collected in the survey (i.e., Gender, Education, Race, Age and Partisanship). Below we display F-Tests that consider the joint significance of these covariates at predicting a respondent's treatment assignment. Failures of randomization would be indicated by a large F-statistic (and small p-value) indicating demographic imbalance between those in one of the treatment conditions, relative to the experiment's control group. 
Table A3: Balance Tests of Survey Treatments in Experiment 3

\begin{tabular}{lrr}
\hline Comparison & F-Statistic & P-Value \\
\hline Neutral-Control & 0.74 & 0.85 \\
Political-Control & 0.68 & 0.90 \\
Attack-Control & 0.79 & 0.80 \\
\hline
\end{tabular}

Reassuringly, across the different treatment control pairings we see these covariates are not able to effectively predict assignment into treatment. The joint tests of significance are null, revealing no systematic association between the covariates and treatment assignment. This supports the random assignment produced groups that did not differ systematically on their background characteristics prior to the experiment. 


\section{B Appendix B: Content Analysis}

\section{B.1 Political Media Portrayals of ESPN}

To produce Figure 1 in the main text, all Fox News transcripts mentioning ESPN from 2005 to 2019 were separately examined by each author $(n=603)$. We examined the transcript to assess whether it invoked political concepts in reference to ESPN. Examples of non-political mentions included the appearance of ESPN personalities to discuss sports or incidental mentions of ESPN in discussions of something else. In contrast, political mentions of ESPN emphasizing the network, or ESPN personalities, held a political perspective (e.g., a liberal political viewpoint, focus on political correctness or social justice) based on sports coverage or personnel decisions. We agreed on our label for $94 \%$ of transcripts. To produce Figure 1, we only count ESPN mentions both coders perceived as politicized.

In Table B1 we provide more examples illustrating that discussion of ESPN in political media extends beyond the coverage of Fox News cable shows examined in the main text. This table displays headlines from articles on right-leaning media sources over the past several years that represent potential sources of politicization from discussions of ESPN on political media.

Table B1: Portrayals of ESPN in Political Media

\begin{tabular}{l|l|l}
\hline Source & Date & Headline \\
\hline Breitbart & $07 / 19 / 2019$ & ESPN Orders Staff to Avoid Pure Politics After Le Batard Rant... \\
Breitbart & $05 / 25 / 2018$ & Bob Ley Warned Execs of Liberal Bias at ESPN... \\
Breitbart & $04 / 28 / 2017$ & How Liberal Politics, Including Obamacare, Hurt ESPN \\
Breitbart & $02 / 15 / 2017$ & Report: ESPN Losing 10,000 Subscribers a Day Over Its Political Left Turn \\
\hline foxnews.com & $09 / 26 / 2018$ & Clay Travis says liberals are ruining sports, wants to 'make sports great again' \\
foxnews.com & $09 / 21 / 2018$ & Disney CEO Bob Iger says ESPN has become too political \\
foxnews.com & $09 / 13 / 2017$ & ESPN's double standard shows when hosts speak out \\
foxnews.com & $08 / 24 / 2017$ & ESPN should be more sports, less politics, Sage Steele says \\
\hline Wall Street Journal & $05 / 24 / 2018$ & How a weakened ESPN became consumed by politics \\
Wall Street Journal & $09 / 15 / 2017$ & Trump Wants Apology Amid Debate Over Whether ESPN Is Biased \\
Wall Street Journal & $05 / 07 / 2017$ & How a Gawker-Affiliated Website Made ESPN Politically Correct \\
Wall Street Journal & $04 / 28 / 2017$ & The Politics of ESPN
\end{tabular}




\section{B.2 ESPN Sports Coverage}

We sample articles from the home page of ESPN's website on ten randomly selected days in $2018(2 / 12,2 / 19,4 / 7,5 / 2,5 / 21,6 / 25,7 / 24,10 / 31,11 / 15,12 / 14)$. On these days, we recorded articles that appeared in the top section of the website in the center of the page and the most prominent sidebar. This produced a sample of 209 ESPN stories.

We had each article assessed by ten coders on Amazon's Mechanical Turk, who saw its headline and the first 150 words of the story when making their assessments. These results are displayed in Table B2. All coders had previously completed a political knowledge quiz that indicated they were familiar with prominent political figures. For the binary categorization of political news coverage displayed in the first column of Table B1, we consider an article "in" the political category if three or more coders considered it to contain political content. We also display the average share of coders who placed the articles in the political category in the second column of Table B2. Finally, the last two columns contain measures of perceived partisan slant of the articles. Higher numbers indicate an article was perceived to favor that party, while lower numbers indicate the article was viewed as negatively discussing that party. This analysis, presented in the first row of Table B2, shows only a small share of the articles from ESPN's front page are seen to contain political content (5\%).

Table B2: Content Analysis of Experimental Treatments and Typical ESPN Sports Coverage

\begin{tabular}{llrrrr}
\hline & Category & Political (Binary) & Political (Share) & Dem Slant & Rep Slant \\
\hline 1 & Front Page Random Sample & 0.05 & 0.06 & -0.01 & -0.00 \\
2 & Politicized Sports Treatments & 0.80 & 0.54 & 0.22 & -0.08 \\
3 & Sports Treatments & 0.00 & 0.03 & 0.03 & -0.03
\end{tabular}

We take two approaches to validating the labels produced by this process. First, alongside this random sample we included five articles previously selected as containing politicized content in a pre-test and three articles that were perceived as not containing any political 
content (See Appendix C), this enables us to check if coders paid attention to the content of these article content during this process. We display the results for these articles in the bottom two rows of Table B2. Four of the five politicized sports articles from Survey 3 were again considered to contain political content based on this classification, reaffirming the label they received in an earlier pre-test (see Appendix C) and the sports articles used throughout Survey 3 were, as in the earlier pre-test, not perceived to contain any political content. This indicates the coders paid attention to article content.

Second, all these articles were subsequently assessed by one of the authors using the same instructions and blinded to the label produced by the MTurk coders. Here the agreement between the expert rating of whether the article was political and the assessment provided by the authors is $97 \%$, providing external validation of this assessment and again affirming the limited amount of politically relevant content placed on the espn.com homepage.

Altogether, this content analysis shows that the politicized sports articles we used in the experiment in Survey 3 are outliers, and that most of the coverage available from ESPN more closely resembles the non-political sports treatments. 


\section{Appendix C: Materials for Experimental Treatments}

This section displays the headlines of the sports articles used in Survey 2 and Survey 3. In Survey 2 all of these sports articles were intended to not convey any political content. In Survey 3 the articles were a mix of coverage with some politicized sports stories and some sports stories that did not contain political content.

\section{C.1 News Exposure Treatments}

In Survey 3 respondents were assigned to either a control condition or one of three treatment categories. Table C3 shows the headlines of the news stories that were used in these treatments. Respondents in a given treatment category were randomly assigned one article from the set of articles in a category. This approach was taken to ensure the treatment effect of a given category did not depend on idiosyncratic features of a single article. In a pre-test all of the articles in the "sports" category were not perceived to have any political content by a set of coders from Amazon's Mechanical Turk. Those in the "politicized sports" category were perceived to contain political content (See Table C4).

Table C1: News Exposure Treatment Articles in Survey 3

\begin{tabular}{l|l}
\hline Category & Headline \\
\hline Sports & Paul Tagliabue, Steve Sabol selected for Pro Football Hall of Fame \\
Sports & USWNT set for World Cup semifinal rematch against England \\
Sports & NBA puts vote on schedule overhaul on hold; still eyes changes \\
\hline Politicized Sports & USWNT wins ruling to pursue gender discrimination suit as class action \\
Politicized Sports & Megan Rapinoe takes home 2019 Ballon d'Or \\
Politicized Sports & Popovich: Kaepernick did 'a very patriotic thing' \\
Politicized Sports & Why recent declarations from Adidas, Nike are important \\
Politicized Sports & NFL owners couldn't care less about inclusive hiring, and it shows \\
\hline Political & ESPN reminds staffers to stick to sports, not talk politics after star rips Trump on-air \\
Political & ESPN slammed for bringing back 'conservative-bashing' Keith Olbermann \\
Political & Ex-ESPN star Jemele Hill doesn't regret calling Trump a white supremacist
\end{tabular}

\section{C.2 Content in News Choice Tasks}

This section displays the sports article headlines that appeared as news choice options in Survey 2 and Survey 3. 
Table C2: Treatment Articles in Survey 2 News Choices

\begin{tabular}{l|l}
\hline Category & Headline \\
\hline Sports & NBA releases schedule: Kawhi in Toronto Dec. 11 \\
Sports & Yes - the Yankees have rotation issues - but they can still win the World Series \\
Sports & How Coco Gauff compares to past tennis prodigies \\
Sports & Fantasy Football Love/Hate for the 2019 season
\end{tabular}

Table C3: Treatment Articles in Survey 3 News Choices

\begin{tabular}{l|l}
\hline Category & Headline \\
\hline Sports & How the Internet helped crack the Astros' sign-stealing case \\
Sports & Why Paul George came to L.A.: 'It was a lot deeper than basketball' \\
Sports & What went wrong with NFL officiating in 2019? \\
Sports & Vandy alum donates $\$ 5$ million to men's basketball program \\
\hline Politicized Sports & New study: Minority coaches still fare worse during NFL hiring process \\
Politicized Sports & Athletes getting back in the protest game \\
Politicized Sports & What does the journey of transgender wrestler Mack Beggs teach us? \\
Politicized Sports & The NFL Racial and Gender Report Card
\end{tabular}

The alternative news selections came from one of eight popular online news sources (Fox News, CNN, Huffington Post, Washington Post, New York Times, BBC, NBC News, CBS News). These alternative headlines were a mix of relatively neutral political stories taken from wire service (e.g., "Sen. Sasse leads calls to use seized 'El Chapo' money to pay for border security") and non-sports, non-political coverage (e.g., "Domino's pizza pie to be delivered using robotic vehicle").

The figures below show how these choice tasks appeared to respondents in Survey 3. 
Figure C1: Example Non-Political Sports News Choice Task Which news item would you prefer to read?

\begin{tabular}{|l||l|l||}
\hline & \multicolumn{1}{|c|}{ News Item A } & \multicolumn{1}{|c|}{ News Item B } \\
\hline \hline Source: & Huffington Post & ESPN \\
\hline \hline \multirow{3}{*}{ Headline: } & $\begin{array}{l}\text { Treasury Watchdog } \\
\text { Will Look Into Delay On }\end{array}$ & How the Internet \\
& $\begin{array}{l}\text { The Harriet Tubman } \\
\text { helped crack the } \\
\text { \$20 Bill }\end{array}$ & $\begin{array}{l}\text { Astros' sign- } \\
\text { stealing case }\end{array}$ \\
\hline
\end{tabular}

News Item A

News Item B

Figure C2: Example Politicized Sports News Choice Task Which news item would you prefer to read?

\begin{tabular}{|l||l|l||}
\hline & \multicolumn{1}{|c|}{ News Item A } & \multicolumn{1}{|c|}{ News Item B } \\
\hline \hline Source: & Fox News & ESPN \\
\hline \hline Headline: & $\begin{array}{l}\text { DOJ announces } \\
\text { release of inmates } \\
\text { as part of criminal } \\
\text { reform }\end{array}$ & $\begin{array}{l}\text { New study: Minority } \\
\text { Coaches still fare } \\
\text { worse during NFL } \\
\text { hiring process }\end{array}$ \\
\hline
\end{tabular}

News Item A

News Item B 


\section{C.3 Coder Assessments of Survey 3 Sports Content}

To select coverage for Survey 3, we had 28 potential sports articles each assessed by 20 coders on Amazon's Mechanical Turk who saw the article's headline and its first 150 words. All of these coders had completed a political knowledge pre-test before proceeding to the classification tasks. They assessed whether or not the article contained political content and, if so, whether the article's content was favorable towards either the Democratic or Republican party on 5-pt scales. In Table C4, we re-code these scales to lie between -1 and 1 .

From this pool of labeled articles, we selected a final set of politicized sports articles based on those articles with the highest proportion of coders identifying them as having political content. In contrast, we selected the articles for the sports category from those with the lowest perceptions of discussing political content by the coders. This creates a sharp distinction between the types of articles that appeared in Survey 3 as treatments in the exposure experiment. In general, the politicized sports articles were regarded as favoring the Democratic party. The sports articles were not seen to favor either political party.

\section{Table C4: Survey 3 Sports Content (News Exposure Treatments)}

\begin{tabular}{|c|c|c|c|c|c|}
\hline & Category & Headline & Share Political & Dem Slant & Rep Slant \\
\hline 1 & Politicized Sports & USWNT wins ruling to pursue gender discrimination... & 0.85 & 0.20 & -0.10 \\
\hline 2 & Politicized Sports & Megan Rapinoe takes home 2019 Ballon d'Or. & 0.65 & 0.20 & -0.05 \\
\hline 3 & Politicized Sports & Popovich: Kaepernick did 'a very patriotic thing' & 0.70 & 0.30 & -0.10 \\
\hline 4 & Politicized Sports & Why recent declarations from Adidas, Nike are important & 0.70 & 0.40 & -0.10 \\
\hline 5 & Politicized Sports & Commentary: NFL owners couldnt care less about inclusive hiring... & 0.45 & 0.20 & -0.20 \\
\hline 1 & Sports & Paul Tagliabue, Steve Sabol selected for Pro Football Hall of Fame... & 0.00 & 0.00 & 0.00 \\
\hline 2 & Sports & USWNT set for World Cup semifinal ... & 0.00 & 0.00 & 0.00 \\
\hline 3 & Sports & Sources - NBA puts vote on schedule tweaks on hold... & 0.00 & 0.00 & 0.00 \\
\hline
\end{tabular}

For the politicized sports news exposure treatments in Survey 3,67\% of coders perceived the articles as discussing politics. They were generally perceived to have a slant that was favorable to Democrats and negative to Republicans. In contrast, the articles in the sports category were not perceived by any coders to have political content $(0 \%$ labeled them as having political content) or a partisan slant to their coverage. 


\section{Table C5: Survey 3 Sports Content (News Choice Options)}

\begin{tabular}{|c|c|c|c|c|c|}
\hline & Category & Headline & Share Political & Dem Slant & Rep Slant \\
\hline 1 & Politicized Sports & The NFL Racial and Gender Report Card & 0.35 & 0.15 & 0.00 \\
\hline 2 & Politicized Sports & Athletes getting back in the protest game & 0.35 & 0.05 & -0.05 \\
\hline 3 & Politicized Sports & New study: Minority coaches still fare worse during NFL hiring process & 0.45 & 0.00 & 0.10 \\
\hline 4 & Politicized Sports & What does the journey of transgender wrestler Mack Beggs teach us? & 0.30 & 0.10 & -0.10 \\
\hline 1 & Sports & What went wrong with NFL officiating in $2019 \ldots$ & 0.05 & 0.05 & 0.00 \\
\hline 2 & Sports & How the internet helped crack the Astros' sign-stealing case & 0.00 & 0.00 & 0.00 \\
\hline 3 & Sports & Why Paul George came to L.A.... & 0.00 & 0.00 & 0.00 \\
\hline 4 & Sports & Vandy alum donates $\$ 5$ million to men's basketball program & 0.00 & 0.00 & 0.00 \\
\hline
\end{tabular}

For the politicized sports news choice options in Survey 3, an average of $36 \%$ of coders perceived articles in this category as discussing politics. They were generally perceived to have a slant that was favorable to Democrats and negative to Republicans. In contrast, the sports articles in the news choice category were generally not perceived by any coders to have political content (an average of $1 \%$ of coders labeled them as having political content) or a partisan slant to their coverage. 


\section{Appendix D: Supplementary Analyses - Partisan Di- vide in Views of ESPN}

This section displays the partisan difference in views of ESPN across the three surveys after conditioning on additional demographic and potliical covariates. This is in contrast to Table 1, which does not include any additional covariates. The coefficients on the "Republican" and "Independent" variables in the table establish that a partisan difference in views of ESPN persists after we account for a variety of characteristics that differ between the po-

litical parties. In other words, these politicized views of ESPN do not appear to simply be a "de facto" association between partisanship and views of the sports network due to the types of people that support different parties.

In the table below the reference category for the partisanship variable is "Democrats", for the political interest variable it is "Hardly at all", for the gender variable it is "Female", for the education variable it is "2-Year Degree" and for the race variable it is "Asian-American." The coefficients for the other variables indicate their difference from these reference categories. 
Table D1: Partisan Divides in Assessments of ESPN (with covariates)

\begin{tabular}{|c|c|c|c|}
\hline & Trust (Survey 1) & Liberal Bias (Survey 2) & Liberal Bias (Survey 3) \\
\hline \multirow[t]{2}{*}{ (Intercept) } & $0.47^{*}$ & 0.03 & -0.09 \\
\hline & $(0.10)$ & $(0.04)$ & $(0.11)$ \\
\hline \multirow[t]{2}{*}{ Independent } & $-0.16^{*}$ & $0.04^{*}$ & 0.01 \\
\hline & $(0.03)$ & $(0.02)$ & $(0.06)$ \\
\hline \multirow[t]{2}{*}{ Republican } & $-0.24^{*}$ & $0.24^{*}$ & $0.11^{*}$ \\
\hline & $(0.03)$ & $(0.01)$ & $(0.05)$ \\
\hline \multirow[t]{2}{*}{ Political Interest-Most of Time } & -0.05 & $0.12^{*}$ & $0.19^{*}$ \\
\hline & $(0.08)$ & $(0.02)$ & $(0.07)$ \\
\hline \multirow[t]{2}{*}{ Political Interest-Only now and then } & -0.10 & $0.06^{*}$ & 0.04 \\
\hline & $(0.09)$ & $(0.02)$ & $(0.07)$ \\
\hline \multirow[t]{2}{*}{ Political Interest-Some of the time } & -0.06 & $0.08^{*}$ & 0.11 \\
\hline & $(0.08)$ & $(0.02)$ & $(0.07)$ \\
\hline \multirow[t]{2}{*}{ Age } & -0.00 & 0.00 & 0.00 \\
\hline & $(0.00)$ & $(0.00)$ & $(0.00)$ \\
\hline \multirow[t]{2}{*}{ Male } & 0.02 & $0.03^{*}$ & 0.07 \\
\hline & $(0.03)$ & $(0.01)$ & $(0.05)$ \\
\hline \multirow[t]{2}{*}{ Education-4year } & 0.05 & $0.05^{*}$ & 0.09 \\
\hline & $(0.04)$ & $(0.02)$ & $(0.06)$ \\
\hline \multirow[t]{2}{*}{ Education-High School } & -0.01 & 0.02 & 0.12 \\
\hline & $(0.04)$ & $(0.02)$ & $(0.06)$ \\
\hline \multirow[t]{2}{*}{ Education-No HS } & 0.08 & -0.01 & 0.16 \\
\hline & $(0.07)$ & $(0.04)$ & $(0.14)$ \\
\hline \multirow{2}{*}{ Education-Postgrad } & 0.07 & 0.01 & 0.08 \\
\hline & $(0.04)$ & $(0.03)$ & $(0.08)$ \\
\hline \multirow[t]{2}{*}{ Education-Some college } & 0.02 & 0.03 & 0.07 \\
\hline & $(0.04)$ & $(0.02)$ & $(0.06)$ \\
\hline \multirow[t]{2}{*}{ Race-Black } & 0.12 & $0.10^{*}$ & 0.01 \\
\hline & $(0.08)$ & $(0.04)$ & $(0.10)$ \\
\hline \multirow{2}{*}{ Race-Hispanic } & -0.01 & 0.03 & -0.05 \\
\hline & $(0.08)$ & $(0.04)$ & $(0.10)$ \\
\hline \multirow[t]{2}{*}{ Race-Other } & 0.00 & 0.01 & -0.07 \\
\hline & $(0.08)$ & $(0.04)$ & $(0.10)$ \\
\hline \multirow{2}{*}{ Race-White } & 0.09 & -0.01 & -0.03 \\
\hline & $(0.07)$ & $(0.03)$ & $(0.09)$ \\
\hline \multirow[t]{2}{*}{ Sports Website Visits/Day } & -0.00 & & \\
\hline & $(0.00)$ & & \\
\hline \multirow[t]{2}{*}{ Sports Interest } & & $0.04^{*}$ & 0.03 \\
\hline & & $(0.02)$ & $(0.06)$ \\
\hline$N$ & 949 & 5009 & 480 \\
\hline
\end{tabular}




\section{E Appendix E: Supplementary Analyses - Sources of Politicization}

\section{E.1 Relationship Between Media Outlet Trustworthiness and Sen- timent (Survey 1)}

Measures of source trustworthiness often appear in the political communication literature and we build on this work by including ESPN in a battery with political news sources. Even when applied to a sports news source, we view this measure as relevant because it taps into overall sentiment towards the sports network, with those who like the network rating it as more trustworthy than those who do not like it. This makes it relevant to understand whether partisanship predicts differences on this outcome.

While we cannot directly support this claim for ESPN, we provide some empirical support for our view of trustworthiness as a reasonable proxy for overall sentiment towards a media outlet by examining the correlation between trustworthiness and feeling thermometers for other media sources where both measures were included in the survey. For four news sources (New York Times, Fox News, Huffington Post and Breitbart) that can be compared in this way, there is an average correlation of .88 between the trustworthiness measure and the feeling thermometer rating respondents provided.

Table E1: Trustworthiness-Feeling Thermometer Correlation by Source

\begin{tabular}{llr}
\hline & Source & Trust-Therm Correlation \\
\hline 1 & New York Times & 0.90 \\
2 & Fox News & 0.89 \\
3 & Huffington Post & 0.85 \\
4 & Breitbart & 0.87 \\
\hline
\end{tabular}




\section{E.2 Alternative Measures of Political and Sports Media Exposure (Survey 1)}

As there are several ways to operationalize political and entertainment media exposure in the web traffic data, here we show the robustness of our findings to alternative specifications. First, instead of combining political media exposure into a single variable, we separately consider the role of Fox News, the most prominent right-leaning media source that offered critiques of ESPN. Second, we consider different ways of measuring exposure to ESPN's website. These alternatives are show in the table below and other than the change in these variables, the regressions remain the same as those presented in Table 2 in the main text.

Table E2: Trustworthiness of ESPN by Online Media Exposure

\begin{tabular}{|c|c|c|c|c|}
\hline 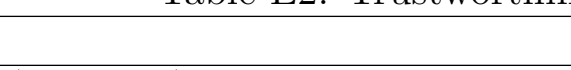 & Alt Fox 1 & Alt Fox 2 & Alt ESPN 1 & Alt ESPN 2 \\
\hline (Intercept) & $\begin{array}{r}0.59^{*} \\
(0.09)\end{array}$ & $\begin{array}{c}0.56^{*} \\
(0.09)\end{array}$ & $\begin{array}{r}0.48^{*} \\
(0.09)\end{array}$ & $\begin{array}{c}0.49^{*} \\
(0.09)\end{array}$ \\
\hline Fox Visitor & $\begin{array}{r}-0.05^{*} \\
(0.02)\end{array}$ & & & \\
\hline ESPN Visitor & $\begin{array}{r}0.05^{*} \\
(0.02)\end{array}$ & $\begin{array}{r}0.04^{*} \\
(0.02)\end{array}$ & & \\
\hline Fox Daily Visits & & $\begin{array}{c}-0.02^{*} \\
(0.01)\end{array}$ & & \\
\hline Right-Leaning Media Exposure & & & $\begin{array}{r}-0.18^{*} \\
(0.03)\end{array}$ & $\begin{array}{r}-0.18^{*} \\
(0.03)\end{array}$ \\
\hline ESPN Daily Visits & & & $\begin{array}{c}0.02^{*} \\
(0.01)\end{array}$ & \\
\hline ESPN-Other Sports Daily Visits & & & & $\begin{array}{c}0.00 \\
(0.01)\end{array}$ \\
\hline$N$ & 926 & 926 & 926 & 926 \\
\hline
\end{tabular}

In the first two columns of the table we see that exposure to Fox News when operationalized as a binary variable (column 1) or by the number of daily visits made by respondents (column 2) predict more negative views of ESPN. In the third column, a continuous measure of the number of daily visits made by respondents to ESPN, an alternative to the binary measure 
of ESPN use presented in the main text predicts more positive evaluations of the sports network. Finally, in the fourth column a continuous measure of the difference between the number of daily ESPN visits minus the number of daily visits to other sports websites is positively related to views of ESPN, but is not statistically significant. We note that one source of imprecision in this difference measure is that both ESPN use and visits to other sports websites are associated with more positive views of ESPN. In general these alternative specifications support the findings presented in Table 2 of the main text.

\section{E.3 Political News Exposure by PID Interactions (Survey 1)}

While Table 2 in the main text breaks out the results separately for each party, here we formally test for heterogeneity in the relationship between right-leaning political media exposure and evaluations of party by ESPN. Here the association between political media exposure and assessments of ESPN is not statistically significant among Democrats, but the interaction coefficients indicate it is much larger among both Independents and Republicans. 
Table E3: Trustworthiness of ESPN by Online Media Exposure

\begin{tabular}{lr}
\hline & Interaction \\
\hline (Intercept) & $0.51^{*}$ \\
& $(0.09)$ \\
Right-Leaning Media Exposure & -0.02 \\
& $(0.06)$ \\
Independent & $-0.19^{*}$ \\
& $(0.03)$ \\
Republican & $-0.19^{*}$ \\
& $(0.03)$ \\
ESPN Visitor & $0.04^{*}$ \\
& $(0.02)$ \\
Right-Leaning Media Exposure $\times$ Independent & $-0.38^{*}$ \\
& $(0.09)$ \\
Right-Leaning Media Exposure $\times$ Republican & $-0.18^{*}$ \\
& $(0.07)$ \\
\hline$N$ & 926 \\
\hline Models condition on partisanship and demographic variables & \\
Partisan Reference Category is Democrats & \\
Standard errors in parentheses & \\
$*$ indicates significance at $p<0.05$ &
\end{tabular}

\section{E.4 2016 Sports News Exposure (Survey 1)}

A drawback of our analysis in Table 2 of the main text is that we may miss those who began to avoid ESPN based on the types of sports coverage it provided. In the table below, we address this as best as we are able to by focusing on ESPN exposure from August to November 2016, a period that is roughly two years prior to the time in which we assessed views of ESPN among these respondents in a September 2018 survey. 
Table E4: Trustworthiness of ESPN by Online Media Exposure (2016 ESPN Visitor)

\begin{tabular}{lccrr}
\hline & All & Democrats & Independents & Republicans \\
\hline (Intercept) & $0.48^{*}$ & 0.28 & 0.56 & 0.17 \\
& $(0.11)$ & $(0.19)$ & $(0.31)$ & $(0.30)$ \\
Partisan Media Exposure & $-0.19^{*}$ & -0.00 & $-0.39^{*}$ & $-0.18^{*}$ \\
& $(0.04)$ & $(0.07)$ & $(0.11)$ & $(0.06)$ \\
ESPN Visitor & $0.05^{*}$ & 0.04 & 0.04 & $0.08^{*}$ \\
& $(0.02)$ & $(0.03)$ & $(0.07)$ & $(0.04)$ \\
\hline$N$ & 660 & 347 & 85 & 228 \\
\hline Models condition on partisanship and demographic variables \\
Standard errors in parentheses \\
${ }^{*}$ indicates significance at $p<0.05$
\end{tabular}

We observe a similar pattern when we only examine the relationship between online news use and views of ESPN among respondents who were part of the panel in 2016. Among this group we see a similar pattern in which exposure to ESPN is related to more positive views of the sports network. To the extent we are able, this helps to address the concern that our analysis in the main text misses people who began to avoid ESPN after this period of time.

\section{E.5 Treatment by PID Interactions (Survey 3)}

In the main text we estimate separate regressions for each group of partisans in Table 3. Below, we more formally test for differences in the effect of the media exposure treatments below by interacting the treatments with party id. Here the baseline coefficients on the treatments indicate the effects of each treatment among Democrats. The interaction coefficients indicate the difference in the treatment effects among Independents and Republicans. 
Table E5: Effects of Media Exposure on Perception of ESPN as Liberal (Interaction Model)

\begin{tabular}{lc}
\hline & Interaction \\
\hline (Intercept) & $0.22^{*}$ \\
& $(0.03)$ \\
Independent & -0.05 \\
& $(0.05)$ \\
Republican & $0.11^{*}$ \\
& $(0.04)$ \\
Sports & 0.03 \\
& $(0.04)$ \\
Politicized Sports & 0.04 \\
& $(0.04)$ \\
Political News & $0.12^{*}$ \\
& $(0.04)$ \\
Sports $\times$ Independent & -0.04 \\
& $(0.07)$ \\
Sports $\times$ Republican & -0.03 \\
& $(0.06)$ \\
Politicized Sports $\times$ Independent & 0.02 \\
& $(0.08)$ \\
Politicized Sports $\times$ Republican & 0.04 \\
& $(0.06)$ \\
Political News $\times$ Independent & -0.08 \\
& $(0.08)$ \\
Political News $\times$ Republican & 0.00 \\
& $(0.07)$ \\
\hline$N$ & 2000 \\
\hline Robust standard errors in parentheses & \\
$*$ indicates significance at $p<0.05$ &
\end{tabular}

From this table it can be seen that none of the PID by treatment interactions reaches statistical significance and they are generally small in size. This lack of large interaction with these variables aligns with the interpretation we offer in main text, arguing that these treatment effects largely appear similar when considering the different partisan groups, and that our pooled analysis does not hide significant heterogeneity by political party. 


\section{E.6 Alternative Outcome in Survey Experiment (Survey 3)}

The outcome scale runs from one to seven, with values below four indicating increasing a perception of increasing Liberal/Pro-Democratic bias from ESPN, the scale's midpoint (4) indicating no bias, and values above four indicating increasing levels of Conservative/ProRepublican bias. In this alternative measurement we again find exposure to the political news coverage leads respondents to perceive ESPN as more liberal. Unlike with the binary coding used in the main text, under this alternative there is not support for the notion that ESPN's own sports coverage provoked a political response, as exposure to either the politicized sports and sports category does not shift perception's of ESPN's content in a liberal direction.

Table E6: Effects of Media Exposure on Perception of ESPN as Liberal (Continuous DV)

\begin{tabular}{lcccc}
\hline & All & Democrats & Independents & Republicans \\
\hline (Intercept) & $3.75^{*}$ & $3.81^{*}$ & $3.79^{*}$ & $3.66^{*}$ \\
& $(0.06)$ & $(0.09)$ & $(0.13)$ & $(0.12)$ \\
Sports & 0.08 & -0.01 & 0.13 & 0.18 \\
& $(0.09)$ & $(0.12)$ & $(0.19)$ & $(0.17)$ \\
Politicized Sports & 0.02 & 0.04 & 0.06 & -0.02 \\
& $(0.09)$ & $(0.12)$ & $(0.19)$ & $(0.17)$ \\
Political News & $-0.20^{*}$ & -0.16 & -0.01 & -0.34 \\
& $(0.09)$ & $(0.12)$ & $(0.19)$ & $(0.18)$ \\
\hline$N$ & 2000 & 1020 & 272 & 708 \\
\hline Standard errors in parentheses & & & \\
$*$ indicates significance at $p<0.05$ & & &
\end{tabular}




\section{F Appendix F: Supplementary Analyses - News Choice}

\section{F.1 Effects of Experimental Treatments on Sports News Choice}

We create an outcome that is the share of choices where a respondent selected sports content

in Survey 3. We regress this on the treatment category to which respondents were assigned in Survey 3. If politicization reduces use of ESPN, another implication is that those in the political news treatment, where politicized views of ESPN underwent an increase, should have less interest in its sports coverage later in the survey.

Table F1: Effects of Media Exposure on ESPN Use

\begin{tabular}{lccc}
\hline & All & Sports Only & Politicized Sports Only \\
\hline (Intercept) & $0.42^{*}$ & $0.41^{*}$ & $0.42^{*}$ \\
& $(0.01)$ & $(0.02)$ & $(0.02)$ \\
Sports & 0.02 & 0.04 & 0.01 \\
& $(0.02)$ & $(0.02)$ & $(0.02)$ \\
Politicized Sports & 0.00 & 0.00 & 0.00 \\
& $(0.02)$ & $(0.02)$ & $(0.02)$ \\
Political News & -0.00 & 0.00 & -0.00 \\
& $(0.02)$ & $(0.02)$ & $(0.02)$ \\
\hline$N$ & 2000 & 2000 & 2000 \\
\hline
\end{tabular}

Standard errors in parentheses

* indicates significance at $p<0.05$

Consistent with our other results relating politicized views of ESPN with news choice, we find no evidence for this here as there is not a treatment effect of politicized views of ESPN on selection of its content.

\section{F.2 ESPN Choice by Alternative}

In the survey choice tasks analyzed in the main text we pool together the various alternatives that were available when respondents decided whether or not they were interested in ESPN's coverage. In this section we subset the data to isolate how partisanship, perceptions of ESPN as liberal and sports fandom predict selecting ESPN in the choice tasks based on which news source was the other option. Looking at each pairing, we see a pattern similar 
to the overall results described in the main text. The figure below shows the coefficients on these predictors with each row indicating how they appear when considering only choice tasks where a particular alternative news source was available.

Figure F1: Predictors of ESPN Selection (By Alternative News Source)
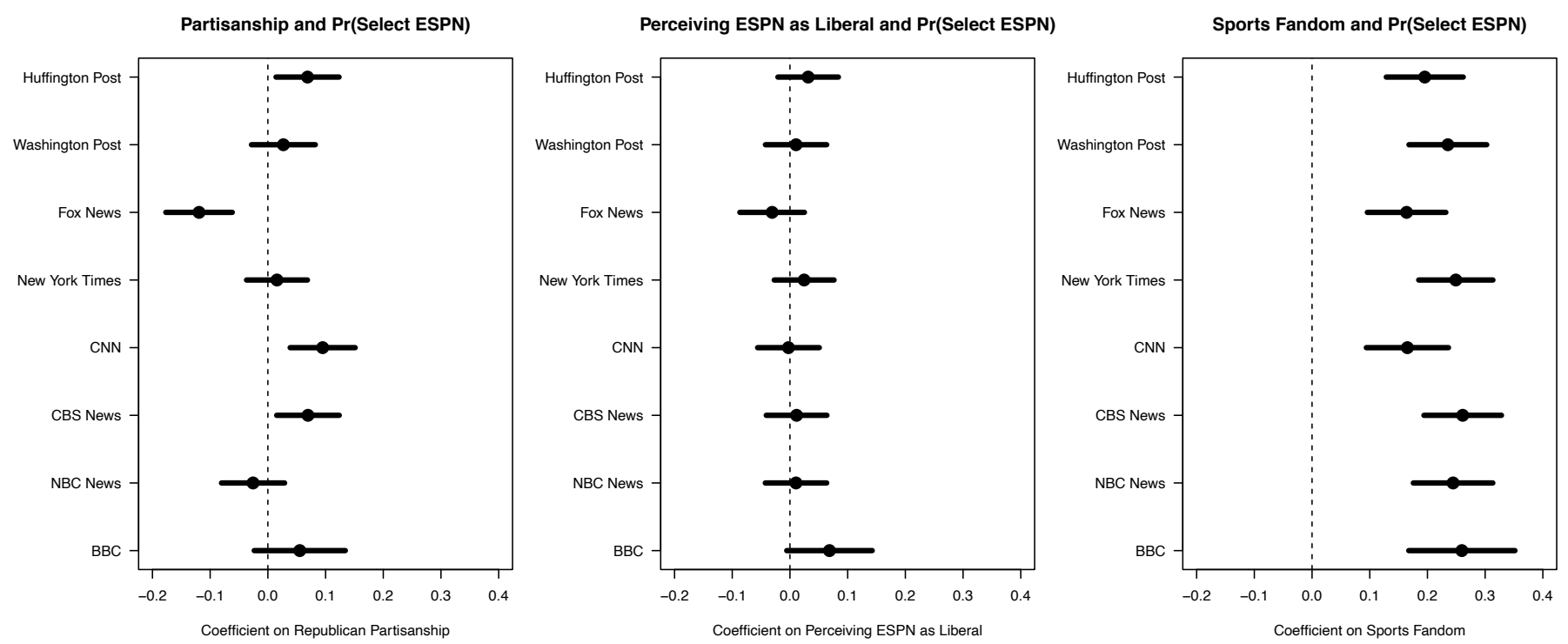

Across these different alternatives, sports fandom is always the strongest predictor of ESPN selection and perceptions of ESPN as liberal generally do not predict choice. There is some variation in partisanship (i.e., Republicans are less likely to select ESPN than Democrats when Fox News is the alternative news source, but are otherwise not across other options), but this variable generally has a limited relationship with ESPN selection.

\section{F.3 Indicators of Sports News Choice Over Time}

Below we consider two supplements to Figure 3 in the main text, by considering other outcomes that may capture whether a partisan divide in sports news choice emerged among the long-term panel. Figure F2 considers the partisan difference in probability of visiting ESPN during this window. 
Figure F2: Partisan Difference in Share of Partisans Visiting ESPN's Website by Month

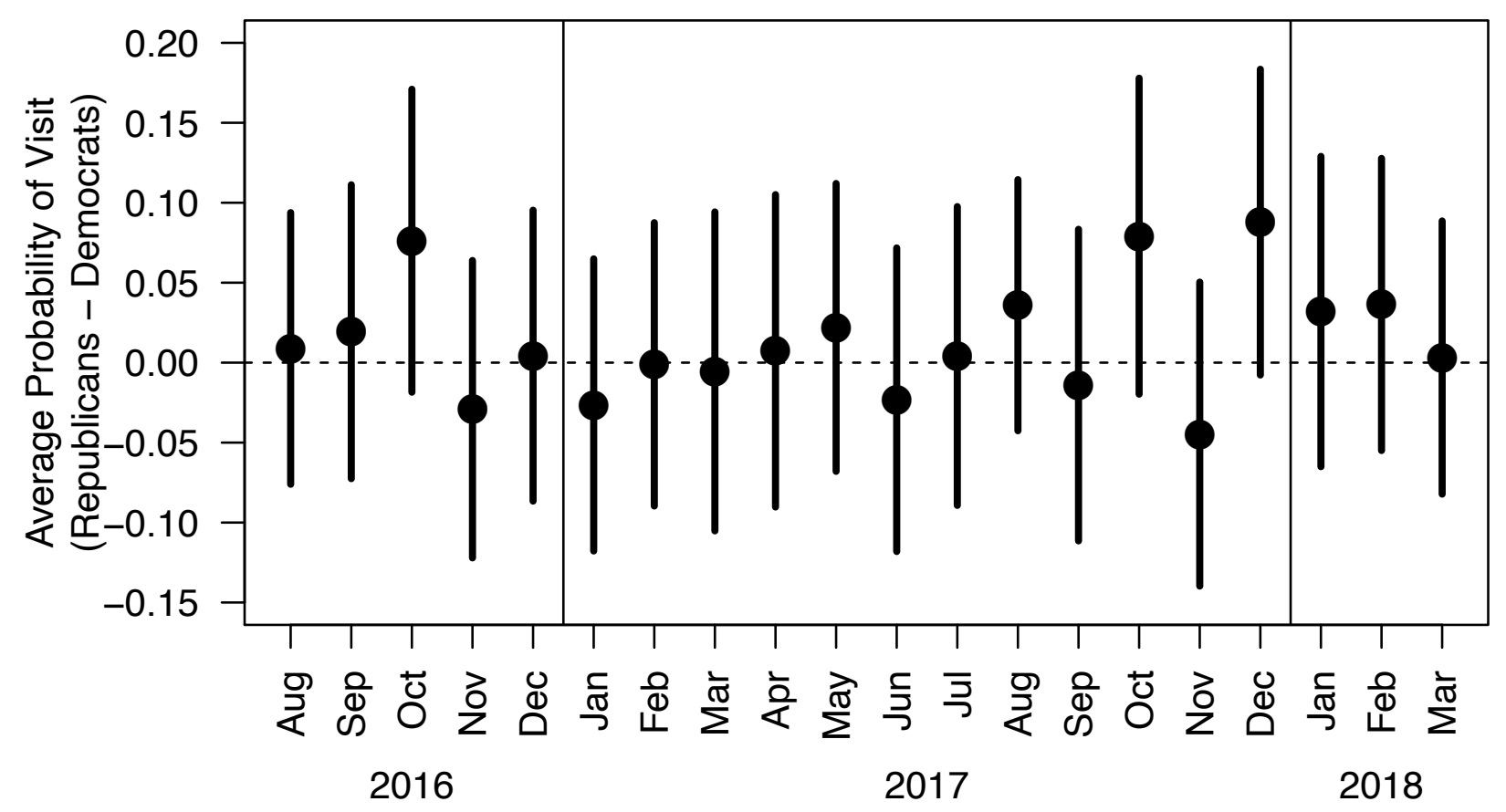

Figure F3 considers the partisan difference between visits to ESPN and visits to other competing sports news websites during this time period. As in the results presented in the main text, in neither case do we observe a partisan trend in Republican's avoidance of ESPN in their sports news consumption over this window or a substantial substantial partisan divide in usage of ESPN at any point during this window. 
Figure F3: Partisan Difference in Average Daily Visits to ESPN and Other Sports Website's by Month

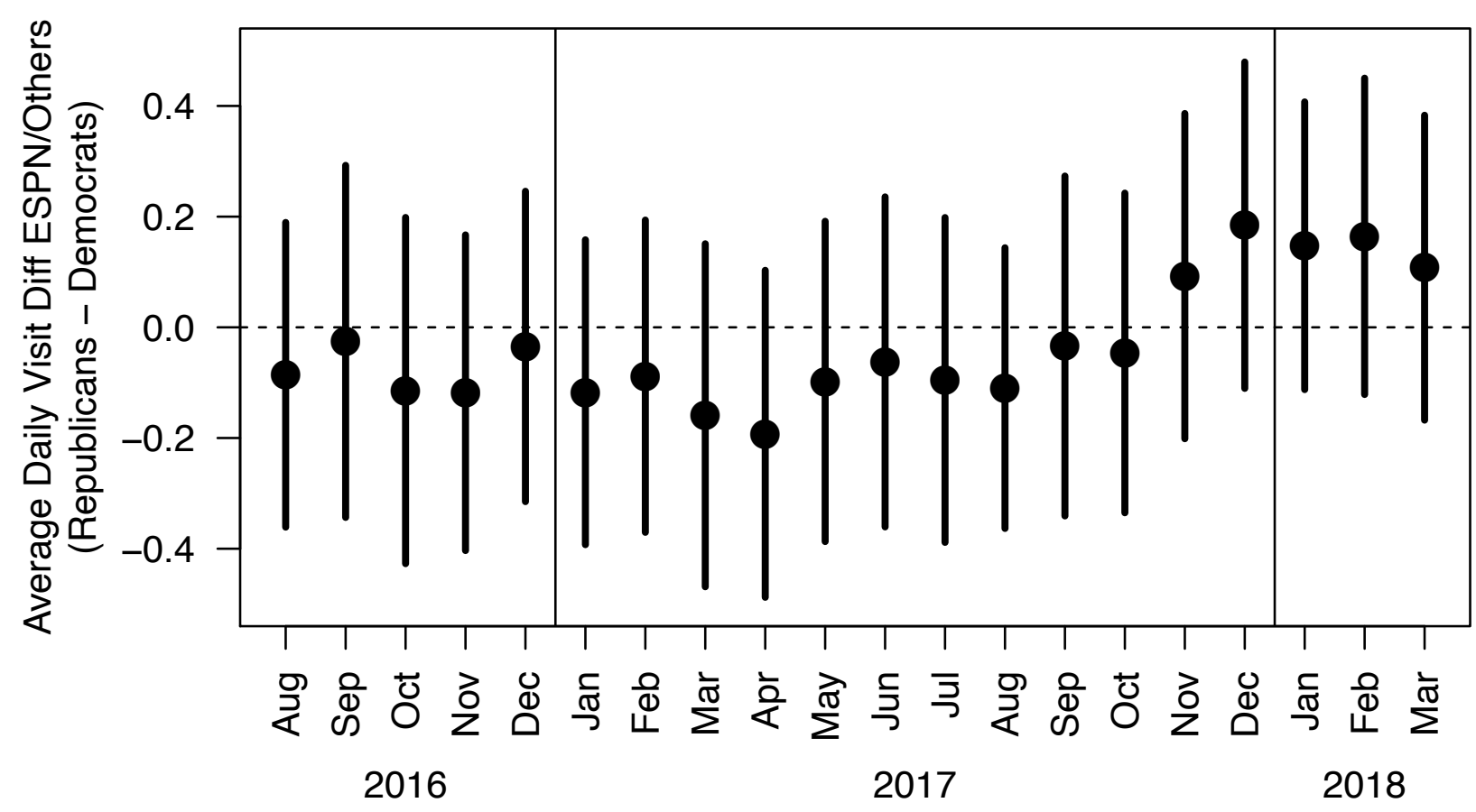

